\title{
Cannabinoid Transmission in the Prefrontal Cortex Bi-Phasically Controls Emotional Memory Formation via Functional Interactions with the Ventral Tegmental Area
}

\author{
Brittany Draycott, ${ }^{1,2}$ - Michael Loureiro, ${ }^{1,2}$ ๑ Tasha Ahmad, ${ }^{1,2}$ Huibing Tan, ${ }^{1,2}$ Jordan Zunder, ${ }^{1,2}$ \\ and Steven R. Laviolette $\mathrm{e}^{1,2,3,4}$ \\ ${ }^{1}$ Addiction Research Group, ${ }^{2}$ Departments of Anatomy and Cell Biology, ${ }^{3}$ Department of Psychiatry, and ${ }^{4}$ Department of Psychology, Schulich School of \\ Medicine and Dentistry. University of Western Ontario, London, Ontario, Canada N6A 5C1
}

Disturbances in cortical cannabinoid CB1 receptor signaling are well established correlates of various neuropsychiatric disorders, including depression and schizophrenia. Importantly, the ability of cannabinoid transmission to modulate emotional processing is functionally linked to interactions with subcortical DA systems. While considerable evidence demonstrates that CB1 receptor-mediated modulation of emotional processing and related behaviors follows a biphasic functional curve, little is known regarding how CB1 signaling within cortical networks may interact with subcortical DAergic systems involved in emotional behavior regulation. Using a combination of in vivo electrophysiological recordings and behavioral pharmacology in rats, we investigated the relationship between $\mathrm{mPFC}$ cannabinoid transmission, fear memory formation, and subcortical DA neuron activity patterns. We report that direct intra-mPFC CB1 activation biphasically modulates spontaneous, subcortical VTA DA neuron activity in a dose-dependent fashion; while lower doses of a CB1 receptor agonist, WIN 55,212-2, significantly increased spontaneous firing and bursting rates of VTA DA neurons, higher doses strongly inhibited spontaneous DA neuron activity. Remarkably, this same dose-related functional difference was observed with the regulation of fear-related emotional memory formation. Thus, lower levels of CB1 activation potentiated the emotional salience of normally subthreshold fear memory, whereas higher levels completely blocked fear memory acquisition. Furthermore, while the potentiation of subthreshold fear memory salience was blocked by DA receptor antagonism, CB1-mediated blunting of suprathreshold fear memory was rescued by intra-VTA administration of $\mathrm{a} \mathrm{GABA}_{\mathrm{B}}$ receptor antagonist, demonstrating that reversal of GABAergic inhibitory mechanisms in the VTA can reverse the inhibitory influence of intra-PFC CB1 transmission on mesolimbic DA activity.

Key words: cannabinoids; dopamine; fear memory; prefrontal cortex; ventral tegmental area

\section{Introduction}

Cannabinoid transmission in the mPFC is involved critically in the processing of emotional information, learning, and memory (Laviolette and Grace, 2006; Tan et al., 2010, 2012; Ahmad et al., 2013). Disturbances in cortical CB1 receptor signaling have been linked to the affective dysregulation features of various neuropsychiatric disorders, including depression and schizophrenia (Andréasson et al., 1987, 1989; Degenhardt et al., 2003; Lynskey et al., 2004). Considerable evidence suggests that cannabinoid signaling modulates emotional processing through biphasic mechanisms. Clinical evidence suggests that exposure to cannabis

Received March 31, 2014; revised Aug. 15, 2014; accepted Aug. 15, 2014

Author contributions: S.R.L., B.D., and M.L. designed research; S.R.L., B.D., M.L., T.A., J.Z., and H.T. performed research; B.D., T.A., and H.T. analyzed data; B.D. wrote the paper.

This work supported by the Canadian Institutes of Health Research and the National Science and Engineering Research Council of Canada.

The authors declare no competing financial interests.

Correspondence should be addressed to Steven R. Laviolette, PhD, Department of Anatomy and Cell Biology, 468 Medical Science Building, University of Western Ontario, London, Ontario, Canada N6A 5C1. E-mail: steven.laviolette@schulich.uwo.ca.

DOI:10.1523/JNEUROSCI.1297-14.2014

Copyright $\odot 2014$ the authors $\quad 0270-6474 / 14 / 3413096-14 \$ 15.00 / 0$ during adolescence increases the likelihood of psychopathology in adulthood, in both humans and other animals (Andréasson et al., 1987, 1989; Abush and Akirav, 2012; Renard et al., 2013; Smith et al., 2014; Szutorisz et al., 2014). Furthermore, heavy cannabis use induces blunting of DA synthesis in marijuana users (Urban et al., 2012; Bloomfield et al., 2014) and neuroanatomical disturbances within mesolimbic structures have been reported in cannabis-using schizophrenia patients, suggesting a functional link between cannabis-related dysregulation of subcortical mesolimbic DA activity and schizophrenia-related cognitive disturbances (Smith et al., 2014).

Cannabinoid CB1 receptors are expressed within the mammalian mPFC (Oropeza et al., 2007; Rey et al., 2012; Fitzgerald et al., 2013) and can modulate mesolimbic DA transmission via bidirectional functional interconnections between the mPFC and VTA (Pistis et al., 2001; Ahmad et al., 2013). Systemic administration of delta-9-tetrahydrocannabinol (THC) or WIN 55,212-2 increases firing rates and bursting activity of VTA DA projecting to the mPFC (French et al., 1997; Gessa et al., 1998). Activation of $\mathrm{CB} 1$ receptors within the prelimbic (PLC) division of the $\mathrm{mPFC}$ strongly potentiates normally nonsalient emotional memory formation and CB1 receptor agonists can potentiate associative neu- 
ronal responses to fear-related conditioned cues (Laviolette and Grace, 2006). However, given the important functional interactions between $\mathrm{CB} 1$ receptor and DAergic signaling within the mesocorticolimbic pathway, a critical question concerns how cortical CB1 receptor transmission may modulate subcortical DAergic activity and how the magnitude of intracortical cannabinoid system activation may regulate DA-dependent emotional processing.

The mPFC and VTA contain both DA and CB1 receptors, which play a critical role in modulating emotionally salient stimuli (French et al., 1997; Laviolette et al., 2005; Laviolette and Grace, 2006; Oropeza et al., 2007; Lauzon et al., 2009; Fitzgerald et al., 2013). Anatomically, the PFC and VTA communicate via ascending and descending functional projections and can bidirectionally modulate neuronal activity dynamics across this pathway (Carr et al., 2000a,b). However, the mechanisms by which intracortical CB1 transmission may regulate subcortical DA transmission and thereby control emotional memory formation are not entirely understood. Using in vivo extracellular recordings directly within the VTA combined with pharmacological modulation of intra-PLC CB1 receptor activation, we investigated the potential functional interactions between cortical CB1 transmission and subcortical DA neuronal activity patterns in the VTA. Using an associative fear-conditioning procedure, we further examined how cortical CB1 transmission may modulate emotional memory formation via functional interactions with GABAergic and DAergic substrates directly within the VTA.

\section{Materials and Methods}

Surgical procedures. Male Sprague Dawley rats (Charles River; 300-350 g) were used for all surgical procedures. All experimental procedures were approved by federal and institutional guidelines for animal care and welfare. Rats were anesthetized with a mixture of ketamine $(80 \mathrm{mg} / \mathrm{ml})$ and xylazine $(6 \mathrm{mg} / \mathrm{ml})$ and placed in a stereotaxic device. Stainless steel guide cannulae (22 gauge; Plastics One) were implanted bilaterally into the VTA or the prelimbic subdivision of the mPFC using the following stereotaxic coordinates (in $\mathrm{mm}$ ): VTA $\left(10^{\circ}\right.$ angle) from bregma: AP $-5.0, \mathrm{~L} \pm 2.6$, from the dural surface, $\mathrm{V}-8.0$; PLC $\left(15^{\circ}\right.$ angle): from bregma, $\mathrm{AP}+2.9, \mathrm{~L} \pm 1.9$; from the dural surface, $\mathrm{V}-3.0$. Cannulae were fixed in place using jeweler's screws and dental acrylic. Following completion of experiments rats were killed with Euthanyl (sodium pentobarbital, $240 \mathrm{mg} / \mathrm{kg}$, i.p.) and perfused with isotonic saline followed by $10 \%$ formalin. Brains were extracted and placed in formalin solution for $24 \mathrm{~h}$ before being placed in a $25 \%$ formalin-sucrose solution for 1 week. Brains were sliced using a cryostat at $40 \mu \mathrm{m}$ and mounted onto slides. Sections were stained with cresyl violet and the placements for mPFC and VTA were verified using light microscopy. Rats with cannula placements found outside the anatomical boundaries of the PLC or VTA, as defined by Paxinos and Watson (2005), were excluded from data analysis.

Drug administration. The following drugs were used during behavioral or electrophysiological experiments: selective CB1 agonist WIN 55,212-2 (Tocris Bioscience), CB1 receptor antagonist AM 251 (Tocris Bioscience), broad-spectrum DA receptor antagonist $c i s-\alpha$-flupenthixol ( $\alpha$-flu; Tocris Bioscience), $\mathrm{GABA}_{\mathrm{A}}$ receptor antagonist bicuculline (Sigma), selective $\mathrm{GABA}_{\mathrm{B}}$ antagonist 2-hydroxy-saclofen (Tocris Bioscience), $\mathrm{GABA}_{\mathrm{A}}$ receptor agonist muscimol (Tocris Bioscience), and $\mathrm{GABA}_{\mathrm{B}}$ receptor agonist baclofen (Tocris Bioscience). WIN 55,212-2 and AM 251 were first dissolved in DMSO and then diluted with physiological saline to reach the desired concentration. All other drugs were dissolved in physiological saline, $\mathrm{pH}$ adjusted to 7.4. During fear conditioning intra-VTA and intra-PFC bilateral microinfusions were performed immediately before the conditioning phase, with $0.5 \mu \mathrm{l}$ total volume per side delivered via a 28 gauge microinfusion injector over a period of $1 \mathrm{~min}$. Microinjectors were left in place for an additional $60 \mathrm{~s}$ following drug infusion to ensure adequate diffusion from the tip. For in vivo electrophysiological recording experiments, $0.5 \mu \mathrm{l}$ of drug was infused over $1 \mathrm{~min}$ via a 26 gauge microinjector implanted into the region of interest. For groups receiving systemic $\alpha$-flu pretreatment before behavioral experiments, rats received $\alpha$-flu $2.5 \mathrm{~h}$ before the conditioning phase. At this dose and time, $\alpha$-flu produces no adverse motivational effects (Laviolette and van der Kooy, 2001).

Fear-conditioning paradigm. Emotional memory formation was examined with an olfactory fear-conditioning paradigm. This procedure is schematically summarized in Figure $1 A$. As previously described (Laviolette and Grace, 2006; Lauzon et al., 2009), by using sub versus supra threshold footshock levels ( 0.4 and $0.8 \mathrm{~mA}$, respectively) we were able to test whether specific drug treatments could block or potentiate the acquisition of either a normally subthreshold versus suprathreshold associative fear memory. Thus, the subthreshold footshock level $(0.4 \mathrm{~mA})$ fails to produce a conditioned fear response at testing whereas a suprathreshold footshock $(0.8 \mathrm{~mA})$ has been shown to produce a robust fear memory (Laviolette and Grace, 2006; Lauzon et al., 2009). For fear conditioning, two distinct test environments are used. Environment $\mathrm{A}$ is a $30 \times 30$ " Plexiglas box with black spots on a white background and environment B is a $30 \times 30$ " Plexiglas box with black and white stripes. The designated "shock" environment had a metallic grid shock floor while the designated "test" environment had a smooth gray Plexiglas floor. The environments were assigned as shock and test in a counterbalanced manner such that all rats with shock environment $A$ were tested in environment B and all rats with shock environment B were tested in environment A. On day one (habituation phase) rats are given sham microinfusions into either the MPFC or the VTA and habituated to both shock and test environments located in a sound-attenuated room for 30 min. On day two (conditioning phase) rats are returned to the room, drug infusions are performed, and the rat is placed in the previously assigned shock environment. Two odors are delivered during the course of conditioning, almond and peppermint. One odor is presented with a footshock (CS+) and the other is presented in the absence of footshock (CS - ). After $1 \mathrm{~min}$ in the shock environment, the CS - odor is presented for $20 \mathrm{~s}$. Two minutes later, the CS+ odor is presented for $19 \mathrm{~s}$ followed by a $1 \mathrm{~s}$ footshock delivered through the metallic grid shock floor. This cycle is repeated five times. On day three (testing phase) rats are placed in the previously assigned test environment. Both CS + and CS - odors are then presented for $5 \mathrm{~min}$. During this time both freezing behaviors and exploratory measures are recorded. Freezing was defined as the absence of all movement aside from respiration. We also examined exploratory scores in response to CS + and CS - presentations, as described previously (Laviolette et al., 2005; Lauzon et al., 2009). We assigned a behavioral exploration score based on the following scale, with each minute of the $5 \mathrm{~min}$ odor presentation scored individually/separately: 0 , no locomotion; 1, ambulation across one side of the testing chamber; 2, ambulation across two sides; 3 , exploration of the full perimeter of the testing chamber; and 4, exploration of the center and entire perimeter of the test chamber. Thus, each animal received a score for both exploratory behavior and percentage of time spent freezing during the test phase to CS+ and CS - presentations.

Footshock sensitivity control experiment. To control for potential nociceptive effects influencing sensitivity to footshock following administration of $\alpha$-flu, we performed a separate series of control experiments to measure footshock sensitivity in vehicle versus the systemically administered doses of $\alpha$-flu $(0.8 \mathrm{mg} / \mathrm{kg}$, i.p. $)$-treated rats. Two groups of rats received either a systemic injection of saline vehicle or $\alpha$-flu $(0.8 \mathrm{mg} / \mathrm{kg}$, i.p. $) 2.5 \mathrm{~h}$ before the sensitivity control tests. Testing took place in a clear, Plexiglas enclosure (the same dimensions as fear-conditioning chambers) placed over an electric grid floor. Subthreshold footshock was administered once every $60 \mathrm{~s}$ over a 5 min period and sensitivity to footshock administration was measured over three separate variables: exploratory behavior scores (as described above), number of jumps in response to footshock administration, and amount (in grams) of defecation during the footshock test session. These behavioral indices of footshock sensitivity are among those reported as reliable indicators of sensitivity to footshock administration (Antoniadis and McDonald, 1999; Laviolette and Grace, 2006). 
A

\section{Day 1 Pre-Conditioning}

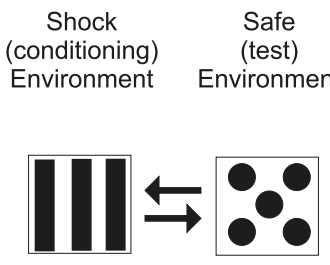

counterbalanced

\section{Day 2 Conditioning}

Supra-threshold

(0.8 mA footshock)

OR

Sub-threshold

(0.4 mA footshock)

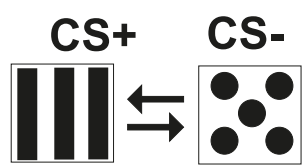

counter-

\section{Day 3 Test Phase}

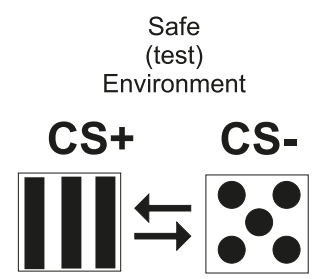

counterbalanced

\section{B}

Figure 1. Methodology and intra-PLC infusions. $\boldsymbol{A}$, Schematic summary describing the olfactory fear-conditioning behavioral protocol. B, Photomicrograph showing typical location of intra-PLC microinfusion location (black arrow), demonstrating location in the PLC relative to the more ventral infralimbic cortex (IFL).

In vivo electrophysiology. In vivo extracellular recordings in the VTA were performed as previously described (Tan et al., 2010). Briefly, rats were anesthetized with urethane $(1.4-1.5 \mathrm{~g} / \mathrm{kg}$, i.p.) and placed in a stereotaxic apparatus. A scalp incision was made and a hole was drilled in the skull overlaying the mPFC and VTA. For intra-PLC microinfusions of vehicle, WIN 55,212-2 or AM 251, a $1 \mu$ l Hamilton syringe was slowly lowered into the PLC using the stereotaxic coordinates described above. For intra-VTA extracellular recordings, electrodes were pulled from borosilicate glass with an average impedance between 6 and $8 \mathrm{M} \Omega$. Microelectrodes were filled with a $2 \%$ Pontamine Sky Blue solution and lowered into the VTA (AP, $-5.3 \mathrm{~mm}$ caudal to bregma; $\mathrm{L}, \pm 0.5-0.8$ $\mathrm{mm}$ ) 7-8.5 $\mathrm{mm}$ ventral to the dural surface. Extracellular signals were amplified using a Multiclamp 700B amplifier (Molecular Devices) and recorded through a Digidata 1440 A acquisition system (Molecular Devices) using pClamp 10 software. Extracellular recordings were typically filtered at $1 \mathrm{kHz}$ and sampled at $5 \mathrm{kHz}$. For electrophysiological investigations, data analysis was accomplished using Clampfit in pClamp 10 software package. DA neurons were identified according to well established electrophysiological features: (1) a relatively longer action potential width $(>2.5 \mathrm{~ms})$, a biphasic waveform consisting of a notch on the rising phase followed by a delayed after-potential; (2) a slow, irregular, or bursting firing pattern; and (3) a spontaneous firing rate of $2-5 \mathrm{~Hz}$. In contrast, non-DAergic VTA neurons were characterized based on previously reported criteria: (1) a narrow action potential width $(<1 \mathrm{~ms}),(2)$ relatively fast firing rates (typically $\sim 10-20 \mathrm{~Hz}$ ), and (3) the absence of bursting activity. Importantly, we only classified a VTA neuron as DAer- gic if, in addition to meeting the criteria outlined above in terms of frequency and waveform properties, the isolated unit displayed bursting activity over the course of baseline recordings, before any subsequent drug microinfusions. Bursting activity parameters were analyzed with well established electrophysiological criteria for in vivo recordings (Grace and Bunney, 1983). The onset of a burst was defined as the occurrence of two consecutive spikes with an interspike interval lower than $80 \mathrm{~ms}$ and terminating with an interval of $>160 \mathrm{~ms}$. We evaluated the amount of bursting activity by calculating the burst-event frequency (number of burst events over time) and the burst size (number of spikes within each burst). Once neurons were isolated based on these criteria, baseline spontaneous activity was recorded for at least 20 min before any drug application. Postdrug application recording epochs lasted between 20 and 60 min, depending upon the stability of the recording. For statistical analyses, we compared pre-infusion recording epochs $(5 \mathrm{~min}$ ) to calculate baseline activity rates. For postinfusion neuronal activity analyses, we isolated the $5 \mathrm{~min}$ neuronal recording epochs immediately following the $1 \mathrm{~min}$ intra-PLC microinfusion and compared these pre versus post infusion recording epochs in terms of firing frequency and bursting parameters. Classification of drug-infusion effects used a criteria of $a \geq 10 \%$ increase in firing frequency post infusion to be classified as an "increase" effect, and a $\leq 10 \%$ to classify as a "decrease" effect. Neurons showing firing frequency or bursting parameters within these cutoff points were classified as "no change." For histological analysis of extracellular VTA neuronal recording sites, recording electrode positions were marked with an iontophoretic deposit of Pontamine Sky Blue dye $(-20 \mu \mathrm{A}$; continu- 
A
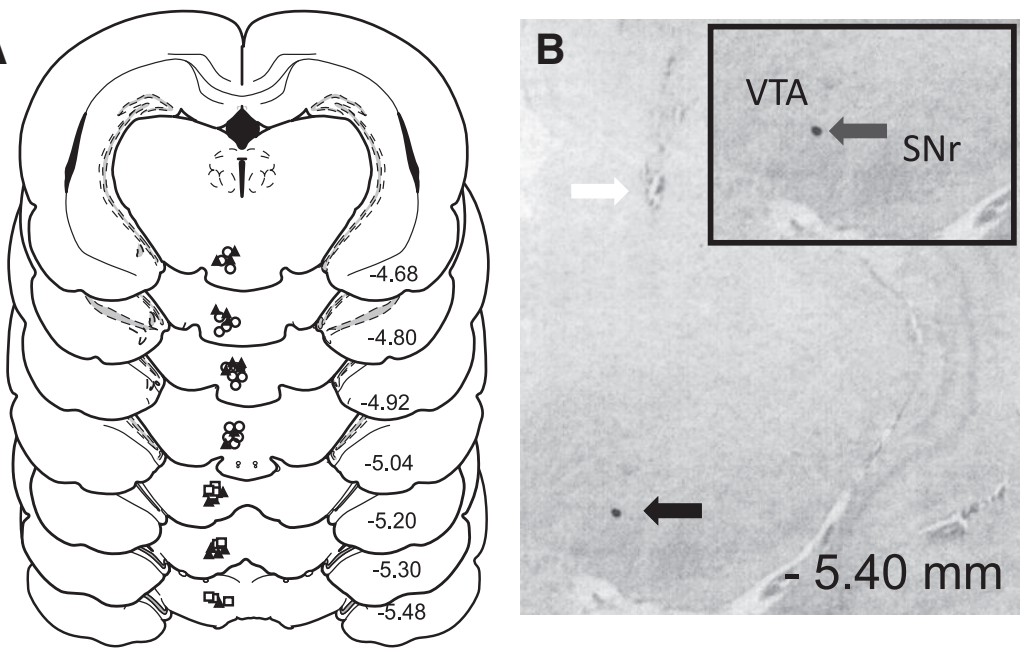

Figure 2. Intra-VTA recording sites. $\boldsymbol{A}$, Schematic presentation showing summary of intra-VTA extracellular recording sites. $\mathbf{\Delta}$, subpopulation of VTA DA neurons showing increased firing rates after intra-PLC WIN 55,212-2 (50 ng/0.5 $\mu \mathrm{l}) ; \bigcirc$, subpopulation of VTA DA neurons showing a decrease in firing frequency following intra-VTA WIN $55,212-2(500 \mathrm{ng} / 0.5 \mu \mathrm{l})$; $\square$, subpopulation of VTA DA neurons isolated for intra-PLC co-microinfusions of WIN 55,212-2 (50 ng/0.5 $\mu \mathrm{l})$ and AM $251(50 \mathrm{ng} / 0.5 \mu \mathrm{l})$. $\boldsymbol{B}$, Photomicrograph showing typical location of intra-VTA extracellular recording site demonstrating iontophoretic marker site for recording location (black arrow) and location of electrode track (white arrow). Inset shows higher magnification of marker location within the VTA (gray arrow). SNr, substantia nigra pars reticulata.

ous current for 10-15 min). The brains were fixed by transcardial perfusion, first with $150 \mathrm{ml}$ of saline; then with $350 \mathrm{ml}$ of $4 \%$ paraformaldehyde in $0.1 \mathrm{~mol} / \mathrm{L} \mathrm{PB}, \mathrm{pH} 7.4$; dissected; postfixed in the same fixative overnight; and transferred to a $25 \%$ sucrose solution for cryoprotection. Coronal sections $(40 \mu \mathrm{m})$ were cut in a cryostat and mounted on gelatin-coated slides. Neutral red staining was used to examine electrode track locations. Sections were rinsed with $0.01 \mathrm{~mol} / \mathrm{L}$ PBS for $5 \mathrm{~min}$, incubated with a $1 \%$ neutral red staining solution for 20 $\mathrm{min}$ at room temperature, and recording sites were verified with light microscopy.

Statistical analyses. Behavioral and/or electrophysiological data were analyzed with one-way or two-way ANOVA or Student's $t$ tests where appropriate. Post hoc analyses were performed with Fisher's LSD tests or Newman-Keuls tests.

\section{Results}

Intra-PLC activation of CB1 receptors biphasically modulates subcortical neuronal activity in the VTA

We first examined the effects of cortical CB1 receptor activation on subcortical DA neuron activity. In Figure $1 B$, we present a microphotograph showing a typical intra-PLC microinfusion location. In Figure 2A, representative intra-VTA recording sites are schematically presented. In Figure $2 B$, we present a microphotograph showing a typical intra-VTA recording site location. For electrophysiological recording experiments, two doses of the selective CB1 agonist, WIN 55,212-2 (50 ng/0.5 and $500 \mathrm{ng} / 0.5 \mu \mathrm{l}$ ), were selected based on previously established, behaviorally effective doses for intracortical infusions (Laviolette and Grace, 2006; Tan et al., 2011; Ahmad et al., 2013). A total of $n=65$ VTA DA neurons was sampled (low-dose WIN 55 group, $n=38$; highdose WIN $55, n=19$ ). A schematic summary of VTA DA neuronal response directions from all sampled neurons following the lower (50 ng) versus higher (500 ng) dose of intra-PLC WIN $55,212-2$ is presented in Figure 3, $A$ and $B$. For rats receiving the lower dose of intra-mPFC WIN $55,50 \%(n=19)$ of neurons showed increased activity, $26 \%(n=10)$ showed decreased activity, and $24 \%(n=9)$ demonstrated no change in activity levels (Fig. $3 A$ ). In contrast, for rats receiving the higher dose of intramPFC WIN 55, 26\% $(n=5)$ of neurons showed increased activ- ity, $63 \%(n=12)$ showed decreased activity, and $11 \%(n=2)$ demonstrated no change in activity levels (Fig. 3B). Comparing pre versus post infusion recording levels across lower versus higher doses of intra-PLC WIN 55,212-2 relative to VTA DA neurons $(n=18)$ recorded from vehicle control-infused rats revealed a significant effect of group $\left(F_{(4,61)}=9.59\right.$; $p<0.001)$. Post hoc analysis revealed that whereas the neuronal subpopulation from the low WIN 55,212-2 dose group showing increased postinfusion firing rates was significantly elevated compared with vehicle controls ( $p<0.01$; Fig. $3 C)$, neurons showing a relative decrease in activity were not significantly different from vehicle controls $(p>0.05)$. In direct contrast, whereas the neuronal subpopulation from the high WIN 55,212-2 dose group showing decreased postinfusion firing rates was significantly depressed compared with vehicle controls ( $p<0.01$; Fig. $3 C$ ), neurons demonstrating a relative increase in activity were not significantly different from vehicle control levels $(p>$ $0.05)$. Thus, lower versus higher doses of intra-PLC WIN $55,212-2$ produced biphasic changes in subcortical VTA DA neuron activity patterns. The lower (50 ng) dose produced significantly increased spontaneous firing activity in a plurality of sampled neurons, whereas the higher (500 ng) dose produced significantly decreased spontaneous firing activity in the majority of sampled neurons.

An intragroup comparison comparing pre versus post infusion firing frequency recording epochs for rats receiving the lower dose of intra-PLC WIN 55,212-2 (50 ng/0.5 $\mu$ l) revealed that the subpopulation of VTA DA neurons (50\%) demonstrating increased firing activity was significantly increased relative to pre-infusion baseline activity $\left(t_{(14)}=2.9 ; p<0.01 ;\right.$ Fig. $\left.4 A\right)$. In Figure $4, B$ and $C$, we present representative rastergrams for two individual VTA DA neurons showing the typically observed increased firing frequency following intra-PLC CB1 receptor activation. An intragroup comparison between pre versus post infusion firing frequency recording epochs for rats receiving the higher dose of intra-PLC WIN 55,212-2 (500 ng/0.5 $\mu$ l) revealed that the subpopulation of sampled VTA DA neurons demonstrating decreased firing activity was significantly decreased relative to pre-infusion baseline activity $\left(t_{(11)}=5.4 ; p<0.001\right.$; Fig. $5 A$ ). In Figure $5 B$, we present a representative rastergram for an individual VTA DA neuron showing the typically observed suppression of spontaneous firing activity following intra-PLC CB1 receptor activation.

Although WIN 55,212-2 is a highly selective agonist of the CB1 receptor, we next ran a pharmacological control experiment to determine that the effects of PLC modulation of subcortical DA neuron activity were mediated through a CB1-dependent substrate. We challenged the effects of the lower, excitatory dose of intra-PLC WIN 55,212-2 (50 ng/0.5 $\mu \mathrm{l}$ ) by simultaneous coadministration with a CB1 receptor antagonist, AM 251 (50 ng/ $0.5 \mu \mathrm{l}$ ). For this experiment, we sampled $n=8$ VTA DA neurons. Intragroup comparison between pre versus post infusion recording epochs revealed no significant difference in firing frequency rates following intra-PLC co-administration of WIN 55,212-2 
with AM $251\left(t_{(7)}=0.37, p>0.05\right.$; Fig. $5 C)$ demonstrating that the excitatory effects of intra-PLC WIN 55,212-2 on subcortical VTA DA neuron activity are dependent on a CB1 receptor substrate in the PLC. In Figure 5D we present a representative rastergram showing the effects on VTA DA neuron spontaneous pre versus post intra-PLC infusion of WIN 55,212-2 with AM 251. We further note that we have previously demonstrated that higher doses of intra-PLC or intraamygdalar WIN 55,212-2 (500 ng/0.5 $\mu \mathrm{l})$ are similarly mediated through pharmacologically specific CB1-dependent mechanisms (Tan et al., 2011; Ahmad et al., 2013).

\section{Intra-PLC activation of $\mathrm{CB} 1$ receptors biphasically modulates DA neuron bursting activity}

We next examined the effects of intraPLC CB1 receptor activation on bursting activity parameters in sampled VTA DA neurons, comparing bursting rates and numbers of spikes per burst between the previously identified DA neuronal subgroups showing relative increases versus decreases in pre versus post WIN 55,212-2 intra-PLC microinfusions (neuronal subpopulations previously identified as not showing significant changes in firing rates were not included in this analysis). First, comparing neuronal subgroups within rats receiving the lower dose of intra-PLC WIN 55 (50 ng/0.5 $\mu \mathrm{l}$ ), two-way ANOVA revealed a significant interaction between group and recording epoch (pre vs post microinfusion) on bursting rates $\left(F_{(1,21)}=6.5 ; p<0.05\right)$. Post hoc analysis revealed that neurons previously demonstrating increased firing activity (Fig. 6A, left) similarly showed postinfusion increases in bursting rate $(p<0.01)$. In comparison, neurons previously demonstrating decreased postinfusion firing activity (Fig. $6 \mathrm{~A}$, right) showed no significant difference in bursting rate $(p>$ $0.05)$. In contrast, two-way ANOVA comparing the average number of spikes per burst across groups revealed no significant effects pre versus post intra-PLC microinfusion of WIN 55,212-2 for any neuronal groups ( $50 \mathrm{ng} / 0.5 \mu \mathrm{l}$; Fig. $6 \mathrm{~B}$ ). Next, comparing neuronal subgroups within rats receiving the higher dose of intra-PLC WIN 55 (500 ng/0.5 $\mu \mathrm{l}$ ), two-way ANOVA revealed a significant interaction between group and recording epoch (pre vs post microinfusion) on bursting rates $\left(F_{(1,31)}=16.4 ; p<\right.$ $0.001)$. Post hoc analysis revealed that neurons previously demonstrating decreased firing activity (Fig. $6 C$, left) demonstrated postinfusion decreases in spontaneous bursting rates $(p<0.01)$. In comparison, neurons previously demonstrating increased postinfusion firing activity (Fig. $6 C$, right) showed no significant difference in bursting rate $(p>0.05)$. In contrast, two-way ANOVA comparing the average number of spikes per burst across groups revealed no significant effects pre versus post intraPLC microinfusion of WIN 55,212-2 (500 ng/0.5 $\mu$ l; Fig. 6D).
Intra-PLC

WIN 55, 212-2

$50 \mathrm{ng} / 0.5 \mu \mathrm{l}$

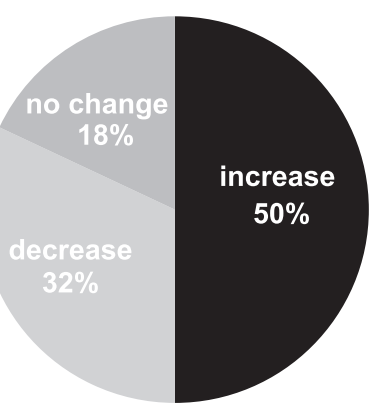

B

Intra-PLC

WIN 55, 212-2

$500 \mathrm{ng} / 0.5 \mu \mathrm{l}$

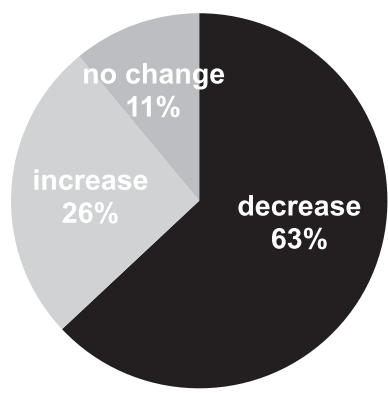

Hiphasic effects of intra-PLC WIN 55,212-2 on intra-VTA neuronal activity. A, Schematic summary showing relative subpopulations of isolated VTA DA neurons in terms of increased $(n=19)$, decreased $(n=10)$, or no change $(n=9)$, in spontaneous firing rates following microinfusions of the lower ( $50 \mathrm{ng} / 0.5 \mu \mathrm{l}$; left) dose of intra-PLC WIN 55, 212-2. B, In contrast, activity $(n=12)$ versus increased $(n=5)$ or no change $(n=2)$ in spontaneous activity rates. C, Summary of group data showing mean changes (relative to baseline) on spontaneous firing frequency in VTA DA neurons following the lower $(n=38)$ versus higher doses $(n=19)$ of intra-PLC WIN 55,212-2.

Thus, intra-PLC WIN 55,212-2 infusion dose dependently increased or decreased spontaneous bursting activity in VTA DA neuronal subpopulations, without significantly influencing the number of spike events within bursts.

\section{Intra-PLC activation of CB1 receptors biphasically controls fear memory formation}

Given the observed biphasic effects on subcortical DAergic transmission, we next examined how these doses modulated the acquisition of associative memories using either a subthreshold ( 0.4 $\mathrm{mA})$ or suprathreshold $(0.8 \mathrm{~mA})$ conditioning dose of footshock in an olfactory fear-conditioning procedure (see Materials and Methods; Laviolette and Grace, 2006; Lauzon et al., 2009). For behavioral experiments, we selected the same lower and higher doses of intra-PLC WIN 55,212-2 as those used in our electrophysiological studies. Furthermore, these doses of intra-PLC WIN 55,212-2 (50-500 ng/0.5 $\mu \mathrm{l})$ are pharmacologically specific for the CB1 receptor in the PLC as we have previously demonstrated that they are completely blocked by co-administration of CB1 receptor antagonists (Laviolette and Grace, 2006, Ahmad et al., 2013). 


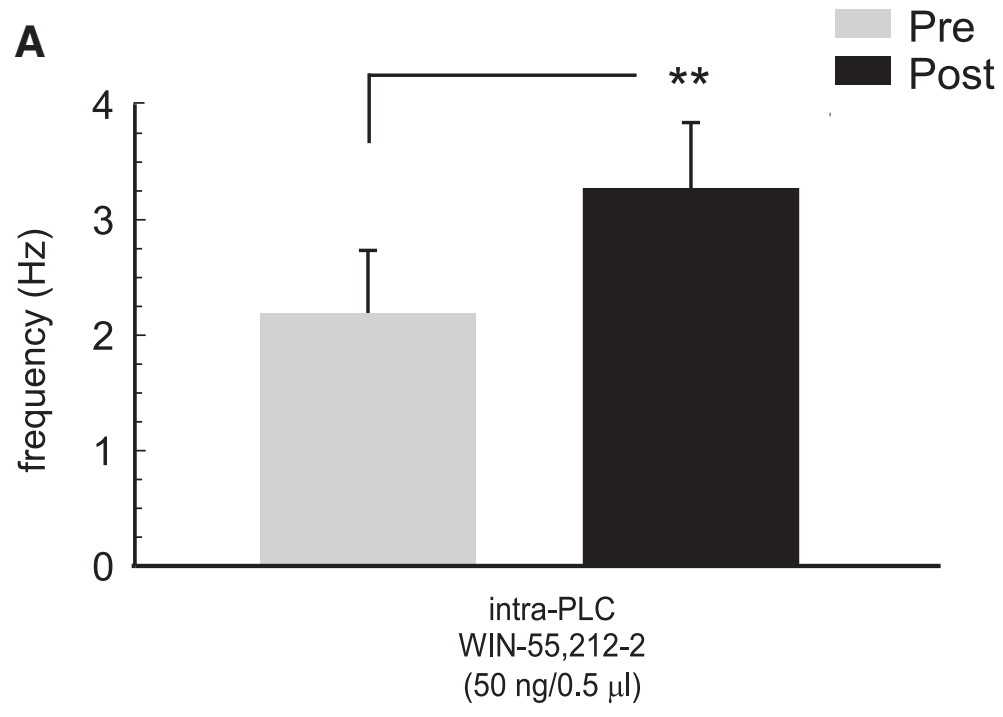

B

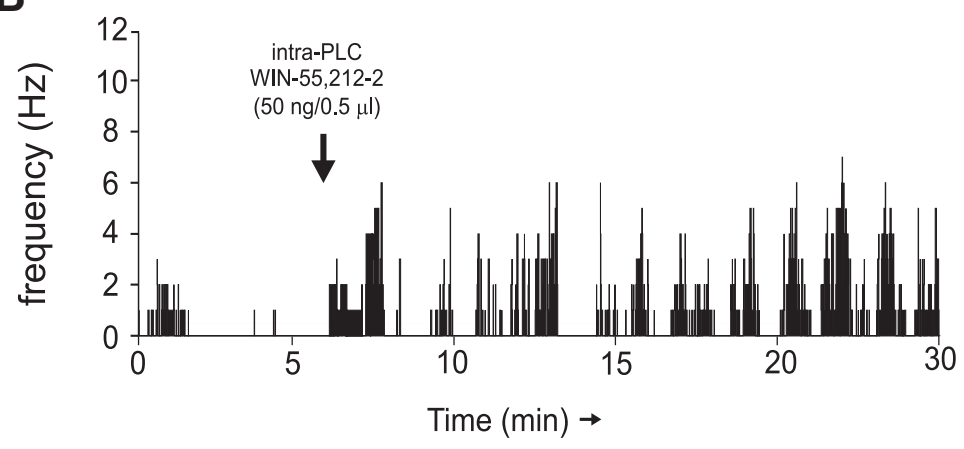

C

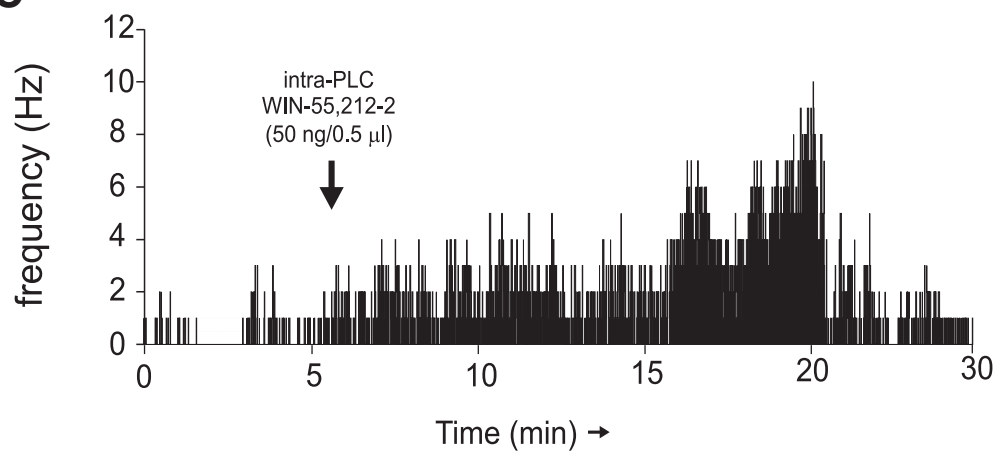

Figure 4. Intra-PLCCB1 activation-induced activation of VTA DA neuron activity. $A$, The subpopulation of VTA DA neurons (50\%; $n=19$ ) demonstrating increased firing activity was significantly increased relative to pre-infusion baseline activity. $\boldsymbol{B}, \boldsymbol{C}$, Representative rastergrams for two individual VTA DA neurons showing the typically observed increased firing activity following intraPLC CB1 receptor activation with the lower dose of WIN 55,212-2 (50 $\mathrm{ng} / 0.5 \mu \mathrm{l})$.

Three-way ANOVA comparing freezing scores during the testing phase for rats receiving a subthreshold, footshock conditioning dose revealed a significant interaction between group and treatment on percentages of freezing $\left(F_{(2,47)}=24.91 ; p<\right.$ $0.0001)$. Post hoc analysis revealed that whereas rats receiving either intra-PLC vehicle infusions $(n=7)$ or rats receiving the higher dose of intra-PLC WIN 55,212-2 (500 ng/0.5 $\mu \mathrm{l} ; n=8$ ) displayed no significant differences in freezing levels between $\mathrm{CS}+$ and $\mathrm{CS}-$ presentations $(p s>0.05$; Fig. $7 A)$, rats receiving a lower dose of WIN 55,212-2 (50 ng/0.5 $\mu \mathrm{l} ; n=10)$ displayed significantly greater freezing specifically in response to CS+ presentations relative to $\mathrm{CS}-$ presentations $(p<0.01$; Fig. $6 A)$. In addition, this group displayed greater $\mathrm{CS}+$-related freezing rela- tive to $\mathrm{CS}+$ freezing levels recorded for either vehicle or higher dose WIN 55,212-2 behavioral groups $(p s<0.01)$.

Three-way ANOVA comparing exploratory behavior scores (see Materials and Methods) revealed a significant interaction between group and treatment on exploratory behavior scores $\left(F_{(2,47)}=\right.$ 20.46; $p<0.0001)$. Post hoc analysis revealed that whereas rats receiving either intra-PLC vehicle infusions $(n=7)$ or rats receiving the higher dose of intra-PLC WIN 55,212-2 (500 ng/0.5 $\mu \mathrm{l} ; n=8)$ displayed no significant differences in exploratory activity levels between CS+ versus $C S-$ presentations $(p s>0.05$; Fig. $7 B)$, rats receiving a lower dose of WIN 55,212-2 (50 ng/0.5 $\mu \mathrm{l} ; n=10)$ displayed significantly greater suppression of exploratory behavior in response to CS+ presentations $(p<0.01$; Fig. $7 B)$. In addition, this group displayed greater CS+-related suppression of exploratory activity relative to either vehicle or higher dose WIN 55,212-2 behavioral groups ( $p s<0.01$ ).

Given our findings that the higher dose of intra-PLC WIN 55,212-2 (500 ng/0.5 $\mu \mathrm{l})$ strongly inhibited spontaneous DAergic neuron activity (Fig. 3B) and failed to potentiate subthreshold-associative footshock memory (Fig. 7A), we next tested whether the higher dose of WIN 55,212-2 would modulate the acquisition of a suprathreshold (0.8 mA) fear memory. Two-way ANOVA comparing freezing scores during the testing phase for rats receiving suprathreshold footshock conditioning revealed a significant interaction between group and treatment on percentage of time spent freezing $\left(F_{(1,31)}=28.61\right.$; $p<0.0001)$. Post hoc analysis revealed that whereas rats receiving either intraPLC vehicle infusions $(n=7)$ demonstrated significantly greater freezing responses in response to $\mathrm{CS}+$ presentations $(p<0.01$; Fig. $7 C)$, rats receiving the higher dose of intra-PLC WIN 55,212-2 (500 ng/0.5 $\mu \mathrm{l} ; n=8$ ) displayed no significant differences in freezing levels between $\mathrm{CS}+$ and $\mathrm{CS}-$ presentations $(p>0.05)$. In addition, this group displayed significantly lower CS+-related freezing relative to $\mathrm{CS}+$ freezing levels recorded for vehicle control groups $(p<0.01)$.

Two-way ANOVA comparing exploratory behavior scores (see Materials and Methods) revealed a significant interaction between group and treatment on exploratory behavior scores $\left(F_{(1,31)}=6.87 ; p<0.05\right)$. Post hoc analysis revealed that whereas rats receiving either intra-PLC vehicle infusions $(n=7)$ displayed or rats receiving the higher dose of intra-PLC WIN 55,212-2 (500 $\mathrm{ng} / 0.5 \mu \mathrm{l} ; n=8$ ) displayed no significant differences in exploratory activity levels between $\mathrm{CS}+$ and $\mathrm{CS}-$ presentations $(p s>$ 0.05; Fig. $7 B)$, rats receiving a lower dose of WIN 55,212-2 (50 $\mathrm{ng} / 0.5 \mu \mathrm{l} ; n=10)$ displayed significantly greater suppression of 

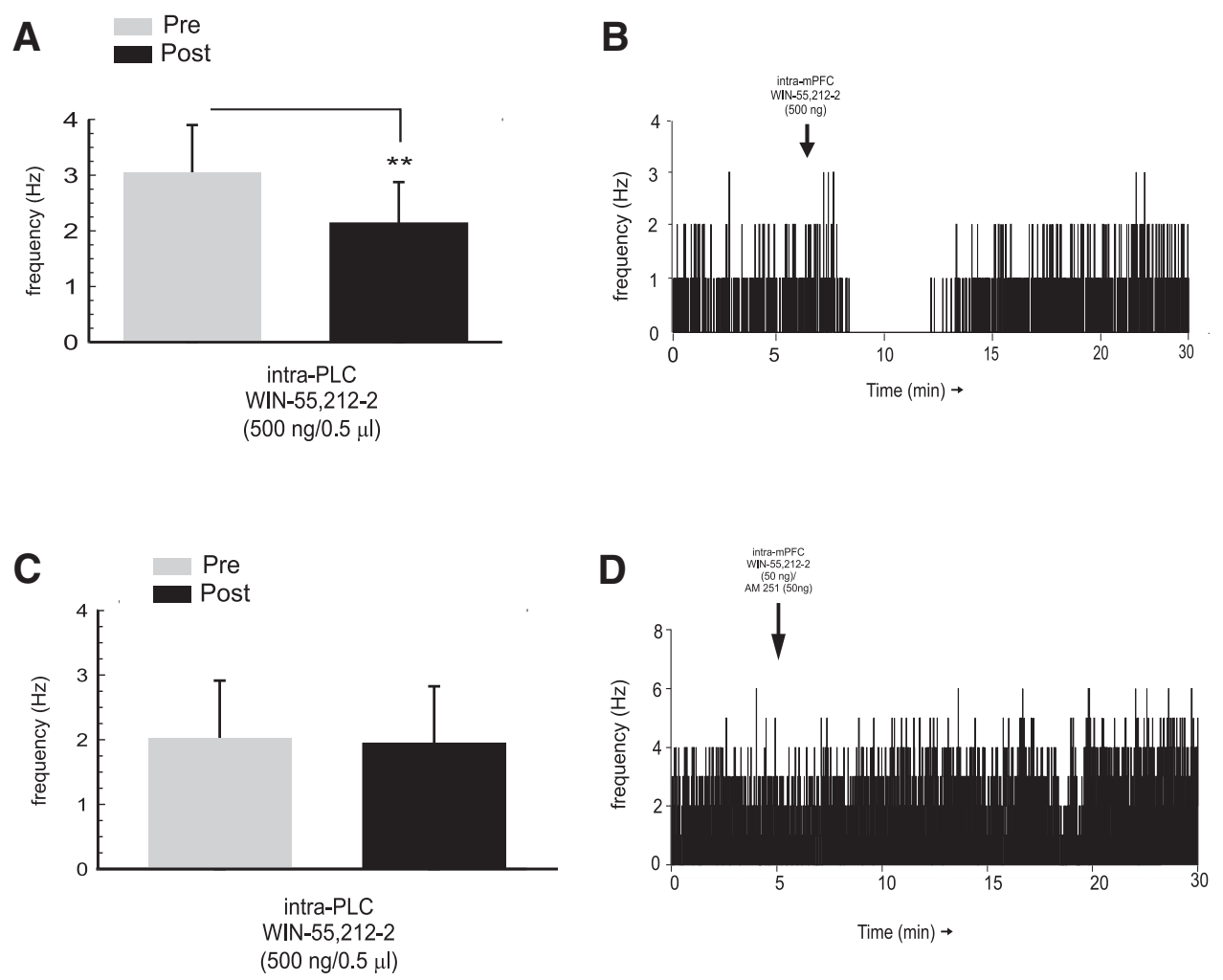

Figure 5. Effects of a higher dose of intra-PLC WIN $55,212-2(500 \mathrm{ng} / 0.5 \mu \mathrm{l})$ on VTA DAergic neuronal activity and pharmacological controls. $A$, The subpopulation of VTA DA neurons $(63 \% ; n=$ 12) demonstrating decreased firing activity were significantly decreased relative to pre-infusion baseline activity. $\boldsymbol{B}$, A representative rastergram for an individual VTA DA neuron showing the typically observed suppression of spontaneous firing activity following intra-PLCCB1 receptor activation with the higher dose of WIN 55,212-2 $(500 \mathrm{ng} / 0.5 \mu \mathrm{l})$. C, VTA DA neurons $(n=8)$ recorded in pharmacological control rats receiving co-administration of WIN 55,212-2 (50 ng/0.5 $\mu$ l) with AM 251 (50 ng/0.5 $\mu$ l) show no difference in spontaneous firing rates pre versus post infusion. $D$, A representative rastergram showing the effects on a VTA DA neuron's spontaneous firing activity pre versus post intra-PLC co-administration of WIN 55,212-2 and AM 251.

exploratory behavior in response to CS + presentations $(p<$ 0.01 ; Fig. $7 B$ ). In addition, this group displayed greater CS+related suppression of exploratory activity relative to either vehicle or higher dose WIN 55,212-2 behavioral groups ( $p s<0.01$ ). Thus, a higher dose of intra-PLC WIN 55,212-2 significantly blocked the acquisition of associative fear memory following conditioning with a suprathreshold level of footshock.

Given that CB1 transmission within cortical areas is known to inhibit GABAergic inhibitory mechanisms (Chiu et al., 2010; Hill et al., 2011; Kiritoshi et al., 2013), we ran separate control groups to determine whether the potential involvement of intra-PLC GABAergic receptor transmission may be differentially involved in either the fear memory potentiating or blunting effects of low versus higher doses of intra-PLC WIN 55,212-2. We therefore co-administered a mixture of the $\mathrm{GABA}_{\mathrm{A}}$ receptor agonist, muscimol $(500 \mathrm{ng} / 0.5 \mu \mathrm{l})$, and the $\mathrm{GABA}_{\mathrm{B}}$ receptor agonist, baclofen (500 ng), with either the lower ( $50 \mathrm{ng} / 0.5 \mu \mathrm{l} ; n=8$ ) or higher (500 ng/0.5 $\mu \mathrm{l} ; n=8$ ) doses of intra-PLC WIN 55,212-2, and examined the behavioral effects of these manipulations on either subthreshold or suprathreshold conditioning levels of footshock, respectively. Analysis of freezing scores for rats receiving the subthreshold level of footshock $(0.4 \mathrm{~mA})$ revealed that coadministration of the $\mathrm{GABA}_{\mathrm{A}} / \mathrm{GABA}_{\mathrm{B}}$ receptor agonists with the lower dose of intra-PLC WIN 55,212-2 (50 ng/0.5 $\mu \mathrm{l}$ ) blocked the ability of CB1 receptor activation to potentiate subthreshold fear memory, as rats displayed no significant difference in levels of freezing to either CS + or CS - cue presentations at testing $\left(t_{(7)}\right.$ $=0.02 ; p>0.05$; Fig. $7 A$, far right). Similarly, no significant difference in suppression of exploratory behavioral scores between CS + and CS - cue presentations was observed $\left(t_{(7)}=0.03\right.$; $p>0.05$; Fig. $7 B$, far right). Analysis of freezing scores for rats receiving the suprathreshold level of footshock $(0.8 \mathrm{~mA})$ revealed that co-administration of the $\mathrm{GABA}_{\mathrm{A}} / \mathrm{GABA}_{\mathrm{B}}$ receptor agonists with the higher dose of intra-PLC WIN 55,212-2 (500 ng/0.5 $\mu \mathrm{l})$ failed to reverse the ability of CB1 receptor activation to block the formation of fear memory to suprathreshold footshock, as rats displayed no significant difference in levels of freezing to either $\mathrm{CS}+$ or CS - cue presentations at testing $\left(t_{(7)}=0.78 ; p>0.05\right.$; Fig. 7C, far right). Similarly, no significant difference in suppression of exploratory behavioral scores between CS + and CS - cue presentations was observed $\left(t_{(7)}=0.80 ; p>0.05\right.$; Fig. $7 D$, far right). Thus, pharmacological activation of $\mathrm{GABA}_{\mathrm{A}} / \mathrm{GABA}_{\mathrm{B}}$ receptors within the PLC blocked the fear memory-potentiating effects of the lower dose of the intra-PLC CB1 agonist, but failed to reverse the fear memory-blocking effects of the higher dose.

\section{Intra-PLC CB1-mediated potentiation of subthreshold fear memory is DA dependent}

Given our findings that intra-PLC CB1 receptor activation strongly potentiated the spontaneous activity of VTA DA neurons and the known ascending DAergic projections from the VTA to the mPFC (Carr and Sesack, 2000a), we next examined the role of DA transmission in the potentiation of subthreshold fear memory with the low dose of intra-PLC WIN 55,212-2 (50 $\mathrm{ng} / 0.5 \mu \mathrm{l})$ using both systemic $(0.8 \mathrm{mg} / \mathrm{kg}$, i.p. $)$ or direct intraPLC administration of $\alpha$-flu $(0.1-1.0 \mu \mathrm{g} / 0.5 \mu \mathrm{l}$; see Materials and Methods). First, comparing freezing behavior at testing for rats receiving co-administration of intra-PLC WIN 55,212-2 with $\alpha$-flu $(0.1-1.0 \mu \mathrm{g} / 0.5 \mu \mathrm{l})$ revealed that intra-PLC blockade of DA transmission blocked the ability of $\mathrm{CB} 1$ receptor activation to 

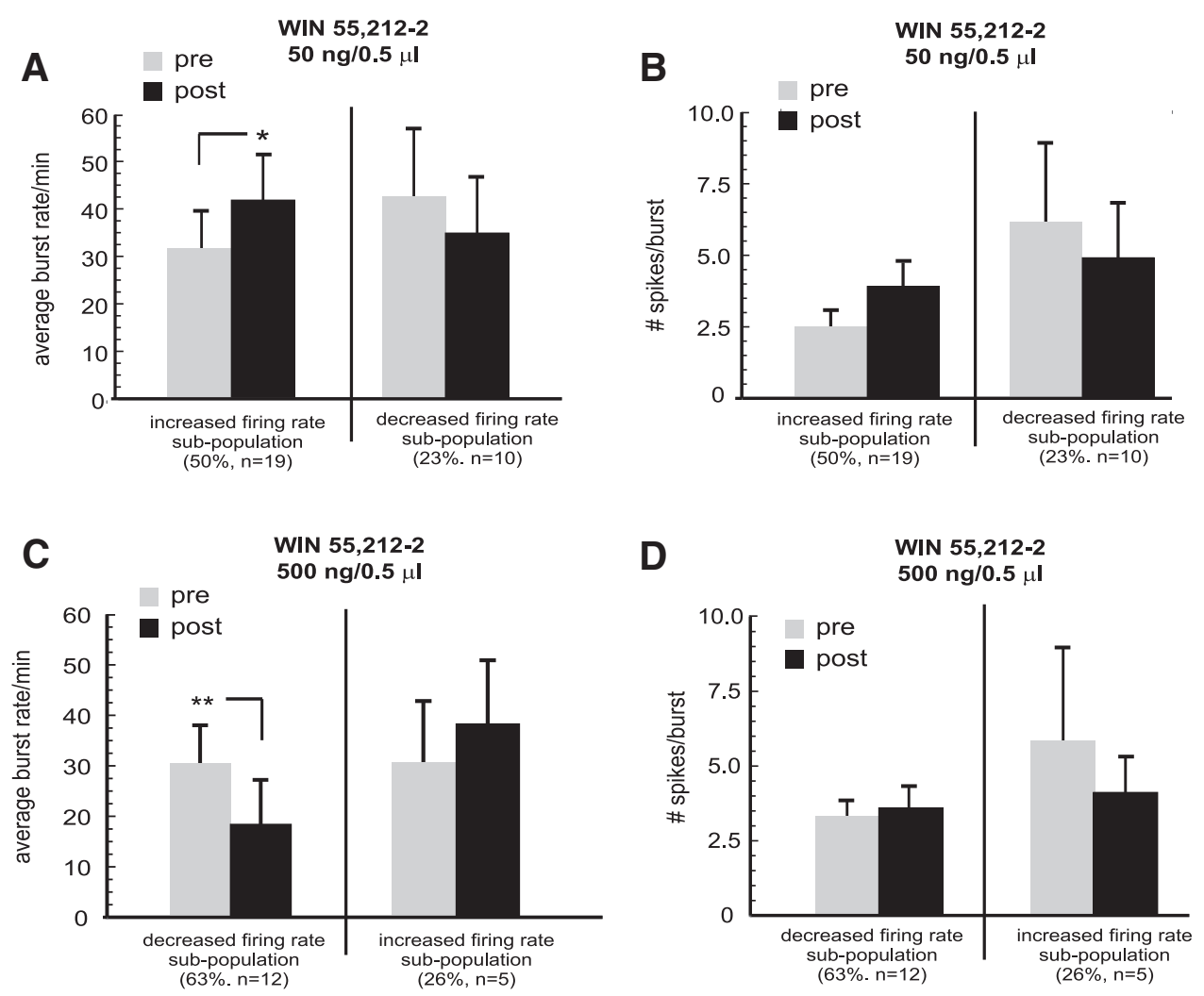

Figure 6. Effects of intra-PLC CB1 receptor activation on VTA DA neuron bursting parameters. A, For rats receiving a lower dose of intra-PLC WIN $55,212-2(50 \mathrm{ng} / 0.5 \mu \mathrm{l})$, the subpopulation of neurons showing increased activity $(n=19)$, but not decreased activity $(n=10)$, demonstrates a significant increase in bursting rate. $B$, In contrast, for these same neuronal subpopulations, no significant increase in spikes per burst event was observed pre versus post infusion. C, For rats receiving a higher dose of intra-PLC WIN 55,212-2 (500 ng/ $0.5 \mu \mathrm{l})$, the subpopulation of neurons showing decreased activity $(n=12)$, but not increased activity $(n=5)$, demonstrates a significant decrease in bursting rate. $\boldsymbol{D}$, In contrast, for these same neuronal subpopulations, no significant increase in spikes per burst event was observed pre versus post infusion.

potentiate normally nonsalient associative fear memory formation (Fig. 8A). Two-way ANOVA comparing freezing scores across groups revealed a significant interaction between group and treatment $\left(F_{(2,39)}=42.7 ; p<0.0001\right)$. Post hoc analysis revealed that whereas vehicle control rats $(n=8)$ displayed greater freezing in response to CS+ presentations $(p<0.01)$, rats receiving either $0.1 \mu \mathrm{g} / 0.5 \mu \mathrm{l}(n=6)$ or $1.0 \mu \mathrm{g} / 0.5 \mu \mathrm{l}(n=6)$ of $\alpha$-flu displayed no increases in CS+-related freezing behavior, indicating no potentiation in emotional fear memory salience for subthreshold footshock conditioning $(0.4 \mathrm{~mA}$; ps > 0.05). Furthermore, both groups receiving intra-PLC a-flu showed significantly less associative freezing behavior relative to vehicle controls $(p s<0.01)$. Comparing exploratory behavior at testing for rats receiving co-administration of intra-PLC WIN 55,212-2 with $\alpha$-flu $(0.1-1.0 \mu \mathrm{g} / 0.5 \mu \mathrm{l})$ revealed that intra-PLC blockade of DA transmission blocked the ability of CB1 receptor activation to induce CS+-related suppression of exploratory behavior to a normally nonsalient associative fear memory formation (Fig. $8 B)$. Two-way ANOVA comparing exploratory behavior scores across groups revealed a significant interaction between group and treatment $\left(F_{(2,39)}=26.8 ; p<0.0001\right)$. Post hoc analysis revealed that whereas vehicle control rats $(n=8)$ displayed greater suppression of exploratory behavior in response to CS + presentations $(p<0.01)$, rats receiving either $0.1 \mu \mathrm{g} / 0.5 \mu \mathrm{l}(n=6)$ or $1.0 \mu \mathrm{g} / 0.5 \mu \mathrm{l}(n=6)$ of $\alpha$-flu displayed no increases in CS+related exploratory behavior suppression, indicating no potentiation in emotional fear memory salience for subthreshold footshock conditioning $(0.4 \mathrm{~mA}$; ps $>0.05)$. Furthermore, groups receiving intra-PLC $\alpha$-flu $(0.1-1.0 \mu \mathrm{g} / 0.5 \mu \mathrm{l})$ showed sig- nificantly greater $\mathrm{CS}+$-related exploratory behavior relative to vehicle controls ( $p<0.01$ and $p<0.05$, respectively).

For rats receiving systemic administration of $\alpha$-flu $(0.8 \mathrm{mg} / \mathrm{kg}$, i.p.; $n=8$ ), comparing freezing behavior at testing for rats receiving co-administration of intra-PLC WIN 55,212-2 following systemic $\alpha$-flu pretreatment (see Materials and Methods) revealed that intra-PLC blockade of DA transmission blocked the ability of $\mathrm{CB} 1$ receptor activation to potentiate normally nonsalient associative fear memory formation (Fig. 8C). Two-way ANOVA comparing freezing scores across groups revealed a significant interaction between group and treatment $\left(F_{(1,29)}=49.3 ; p<\right.$ $0.0001)$. Post hoc analysis revealed that whereas vehicle control rats $(n=8)$ displayed greater freezing in response to CS+ presentations $(p<0.01), \alpha$-flu pretreated rats displayed no increases in CS+-related freezing behavior, indicating no potentiation in emotional fear memory salience for subthreshold footshock conditioning $(0.4 \mathrm{~mA}, p s>0.05)$. Furthermore, $\alpha$-flu pretreated rats showed significantly less associative freezing behavior relative to vehicle controls $(p<0.01)$. Comparing exploratory behavior between groups revealed that $\alpha$-flu pretreatment blocked the ability of CB1 receptor activation to induce CS+-related suppression of exploratory behavior to a normally nonsalient associative fear memory formation (Fig. 8D). Two-way ANOVA comparing exploratory behavior scores across groups revealed a significant interaction between group and treatment $\left(F_{(1,29)}=\right.$ $19.2 ; p<0.001)$. Post hoc analysis revealed that whereas vehicle control rats $(n=8)$ displayed greater suppression of exploratory behavior in response to CS + presentations $(p<0.01), \alpha$-flu pretreated rats displayed no increases in $\mathrm{CS}+$-related exploratory 
A
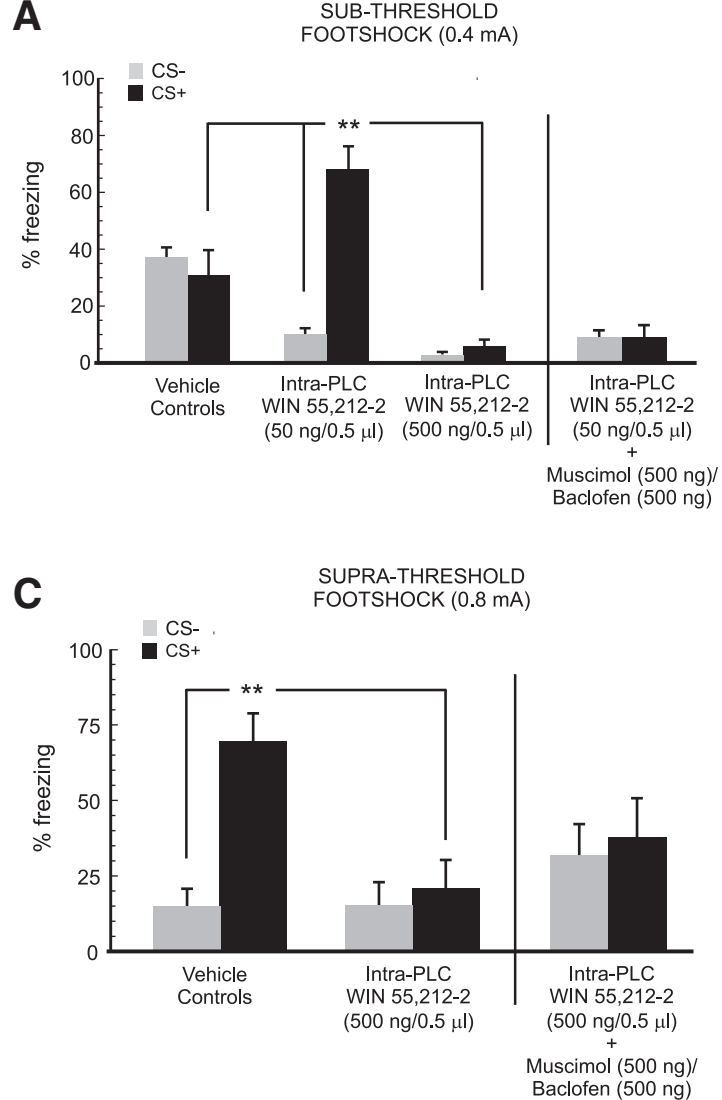
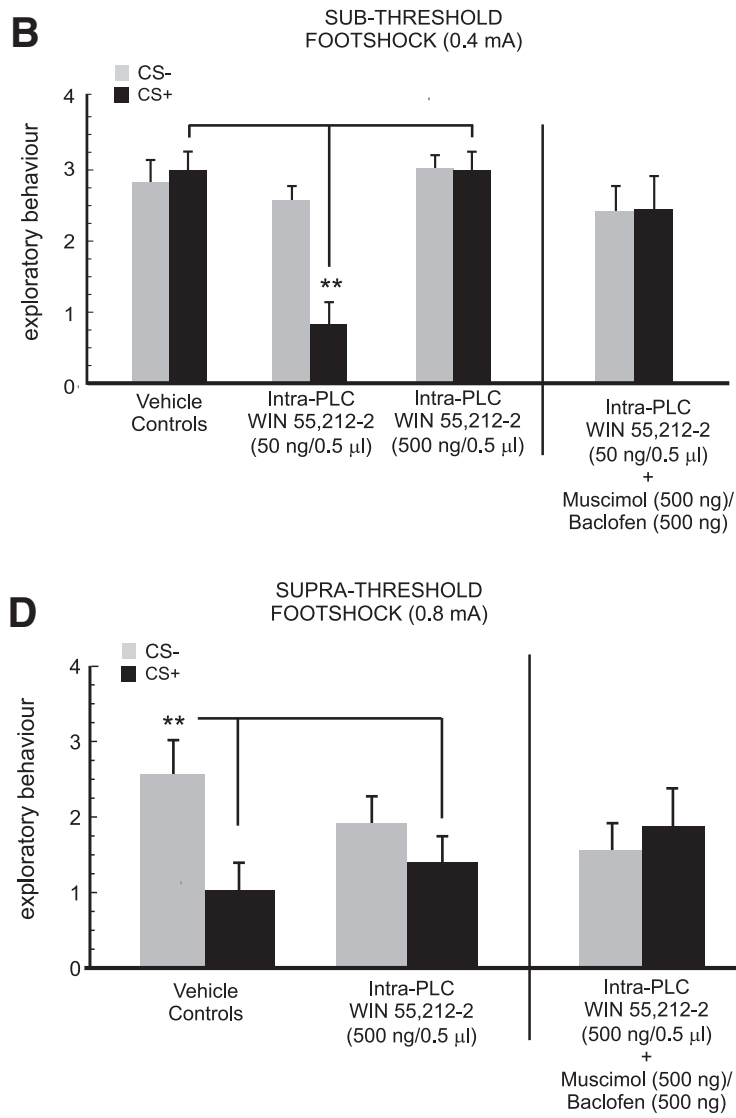

Figure 7. Biphasic behavioral effects of intra-PLCCB1 receptor activation on the acquisition of subthreshold versus suprathreshold fear memory. $\boldsymbol{A}$, Relative to vehicle controls ( $n=7$ ), intra-PLC CB1 activation with a lower dose ( $50 \mathrm{ng} / 0.5 \mu \mathrm{l} ; n=10$ ) of WIN 55,212-2 strongly potentiated normally subthreshold fear memory acquisition measured by freezing behavior. In contrast, a higher dose of WIN 55,212-2 (500 ng/ $0.5 \mu \mathrm{l} ; n=8)$ has no behavioral-potentiating effects. Co-administration with muscimol ( $500 \mathrm{ng})$ and baclofen ( $500 \mathrm{ng})$ with the lower dose of WIN $55,212-2$ blocked fear memory potentiation ( $n=8$; far right). $\boldsymbol{B}$, Similar effects are observed with exploratory behaviors measured during $C S+$ and $C S-$ presentations following subthreshold fear memory conditioning and co-administration with muscimol (500 ng) and baclofen (500 ng) with the lower dose of WIN 55,212-2 blocking associative suppression of exploratory behavior to CS+ presentations (far right). C, In contrast, relative to vehicle controls ( $n=7)$, intra-PLC CB1 activation with a higher dose ( $500 \mathrm{ng} / 0.5 \mu$ l; $n=8)$ of WIN $55,212-2$ blocks the acquisition of a normally suprathreshold fear memory measured by freezing behavior and exploratory behaviors measured during $C S+$ and $C S-$ presentations (D). C0-administration with muscimol ( $500 \mathrm{ng}$ ) and baclofen $(500 \mathrm{ng})$ with the higher dose of WIN 55,212-2 ( $n=8$ ) has no effects on either fear memory blockade or associative suppression of exploratory behaviors ( $\boldsymbol{C}, \boldsymbol{D}$, far right).

behavior suppression, indicating no potentiation in emotional fear memory salience for subthreshold footshock conditioning $(p>0.05)$. Furthermore, $\alpha$-flu pretreated rats showed significantly greater $\mathrm{CS}+$-related exploratory behavior relative to vehicle controls $(p<0.01)$. Thus, both intra-PLC and systemic blockade of DA transmission are sufficient to block the fear memory-potentiating effects of intra-PLC CB1 receptor activation. To rule out the possibility of $\alpha$-flu inducing altered nociceptive processing, we tested the effects of the high, systemic dose of $\alpha$-flu $(0.8 \mathrm{mg} / \mathrm{kg}$, i.p. $)$, which would be expected to block all postsynaptic DA receptors, including intra-PLC DA receptor populations. Testing the effects of $\alpha$-flu administration on sensitivity to subthreshold footshock $(0.4 \mathrm{~mA})$, administration (see Materials and Methods) revealed no significant effects of $\alpha$-flu pretreatment on the number of jumps in response to footshock administration (no quantitative difference between groups) nor in the amount of defecation during the footshock administration period $\left(t_{(12)}=0.59, p>0.05\right)$. We observed a significant attenuation in exploratory behavior in $\alpha$-flu pretreated rats; however, given that this dose of systemic $\alpha$-flu induces cataleptic effects, this behavioral response would be expected (data not shown). In any case, such motoric effects of $\alpha$-flu would be unlikely to influence the behavioral measures of freezing or exploratory behavior during the test phase, as rats are tested $24 \mathrm{~h}$ post injection, in a drug-free state. In addition, exploratory behavior scores in groups receiving $\alpha$-flu pretreatments (Fig. $8 B, D$ ) were comparable to those observed in other groups during the testing phase (Fig. $7 B, D)$.

Intra-PLC CB1-mediated blockade of fear memory formation is mediated through GABAergic signaling in the VTA

Within the VTA, both $\mathrm{GABA}_{\mathrm{A}}$ and $\mathrm{GABA}_{\mathrm{B}}$ receptor substrates critically modulate DAergic and non-DAergic neuronal activity. Thus, it is well established that GABAergic interneurons in the VTA provide inhibitory control over mesocortical DA neurons through $\mathrm{GABA}_{\mathrm{A}}$ receptors associated with inhibitory feedforward interneurons (Kalivas, 1993; Laviolette and van der Kooy, 2001; Laviolette et al., 2004). Further, while $\mathrm{GABA}_{\mathrm{A}}$ receptors are predominantly (although not exclusively) localized to nonDAergic GABAergic VTA neurons (Churchill et al., 1992; Kalivas, 1993), GABA $_{B}$ receptors are more localized on VTA DA neurons (Margeta-Mitrovic et al., 1992; Xi and Stein, 1999) and directly inhibit the activity VTA DA neuron activity (Margolis et al., 2012). Given our previous findings demonstrating strong inhibition of spontaneous VTA DA neuron activity patterns following high-dose administration of the $\mathrm{CB} 1$ agonist, we hypothesized that pharmacological blockade of either $\mathrm{GABA}_{\mathrm{A}}$ and/or $\mathrm{GABA}_{\mathrm{B}}$ receptor transmission directly in the VTA (see Materials and 

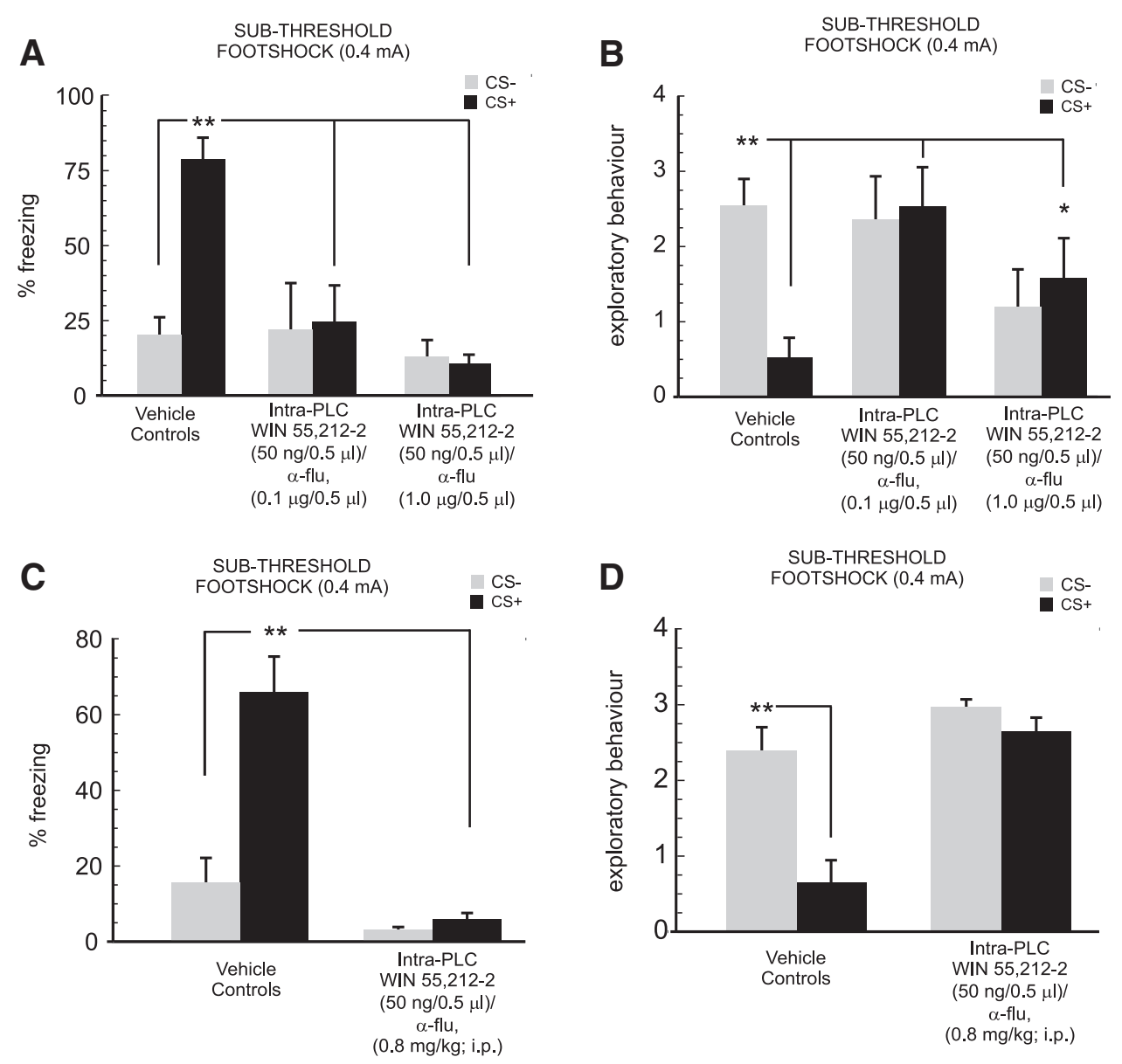

Figure 8. Effects of systemic or intra-PLC DA receptor blockade on CB1-mediated potentiation of subthreshold fear memory. $A$, Relative to vehicle controls $(n=8)$, c0-administration of the DA receptor antagonist, $\alpha$-flu, into the PLC with WIN 55,212-2 (50 ng/0.5 $\mu$ l) blocks the ability of intra-PLC CB1 activation to potentiate subthreshold fear memory measured by freezing behaviors, over an order of magnitude dose range $(0.1-1.0 \mu \mathrm{g} / 0.5 \mu \mathrm{l} ; n s=6$ per group). $\boldsymbol{B}$, Similar effects are observed with conditioned suppression of exploratory behaviors. $C$, Similarly, relative to vehicle controls $(n=8)$, systemic pretreatment with $\alpha$-flu $(0.8 \mathrm{mg} / \mathrm{kg}$, i.p.; $n=8)$ before intra-PLCWIN $55,212-2(50 \mathrm{ng} / 0.5 \mu \mathrm{l})$ blocks the ability of CB1 activation to potentiate subthreshold fear memory measured by freezing behaviors. $\boldsymbol{D}$, Similar effects are observed with conditioned suppression of exploratory behaviors.

Methods) may reverse the inhibitory effect of intra-PLC CB1 activation on VTA DA neuron activity, and hence behaviorally rescue the concomitant block of suprathreshold fear memory acquisition. First, we pretreated the VTA with bilateral microinfusions of the $\mathrm{GABA}_{\mathrm{A}}$ antagonist bicuculline (5-50 ng/0.5 $\mu \mathrm{l}$ ) or vehicle, immediately before intra-PLC WIN 55,212-2 (500 ng/ $0.5 \mu \mathrm{l}$ ) administration (Fig. 9A). [For ease of comparison, we present intra-PLC vehicle controls vs suprathreshold footshock $(0.8 \mathrm{~mA})$ in Figure $9 A, B$ (far left), first shown in Figure $7 C, D]$. Analysis of freezing behavior with two-way ANOVA revealed a significant interaction between group and treatment $\left(F_{(3,61)}=\right.$ 3.05, $p<0.05)$ on the amount of time spent freezing to CS+ versus $\mathrm{CS}-$ presentations. Consistent with previous results (Fig. $7 C)$, post hoc analysis revealed that rats receiving intra-PLC/intraVTA vehicle demonstrated significant levels of conditioned fear, spending a greater amount of time freezing to the CS+ presentation relative to the CS $-(n=8, p<0.01)$. In contrast, animals receiving intra-mPFC WIN 55,212-2 (500 ng/0.5 $\mu \mathrm{l})$ with intraVTA vehicle $(n=8), 5 \mathrm{ng}$ bicuculline $(n=8)$, or $50 \mathrm{ng}$ bicuculline $(n=7)$ showed no associative freezing in response to CS+ presentations ( $p s>0.05$; Fig. $9 A$ ). Interestingly, for rats receiving the higher dose of intra-VTA bicuculline ( $50 \mathrm{ng}$ ), freezing behaviors were significantly elevated relative to vehicle controls for both CS - and CS + presentations ( $p s<0.05$ ), suggesting a generalized, nonassociative increase in behavioral responsiveness to cue presentations. Two-way ANOVA of exploratory behavior scores during $\mathrm{CS}+$ and CS - presentations revealed a significant main effect of treatment $\left(F_{(3,61)}=6.99, p<0.01\right)$. Post hoc analysis showed rats receiving intra-mPFC/intra-VTA vehicle displayed significant suppression of exploratory behavior specifically in response to CS+ presentations $(p<0.01$; Fig. $9 B)$. In contrast, rats receiving intra-PLC WIN 55,212-2 with intra-VTA vehicle or $5 \mathrm{ng}$ or $50 \mathrm{ng}$ bicuculline showed no significant difference in exploratory behavior during CS + versus CS - presentations $(p s>0.05)$.

Next, to examine the potential effects of intra-VTA GABA $_{B}$ receptor transmission, we performed additional experiments with the highly selective $\mathrm{GABA}_{\mathrm{B}}$ receptor antagonist, hydroxysaclofen (10-100 ng/0.5 $\mu \mathrm{l}$; see Materials and Methods). Twoway ANOVA examining freezing behavior revealed a significant interaction between group and treatment $\left(F_{(3,55)}=4.12, p<\right.$ 0.05). Post hoc analysis revealed that rats receiving intra-mPFC WIN 55 with the higher dose of intra-VTA hydroxy-saclofen (100 ng, $n=6$ ) demonstrated significantly greater freezing behavior to the CS+ presentations $(p<0.01$; Fig. $9 A)$. In contrast, rats receiving intra-mPFC WIN 55 with a lower dose of intra-VTA hydroxy-saclofen (10 ng, $n=6$ ) demonstrated associative freezing $(p>0.05)$, similar to intra-VTA vehicle controls. Two-way ANOVA of exploratory behavior scores during CS+ and CSpresentations revealed a significant interaction between group 


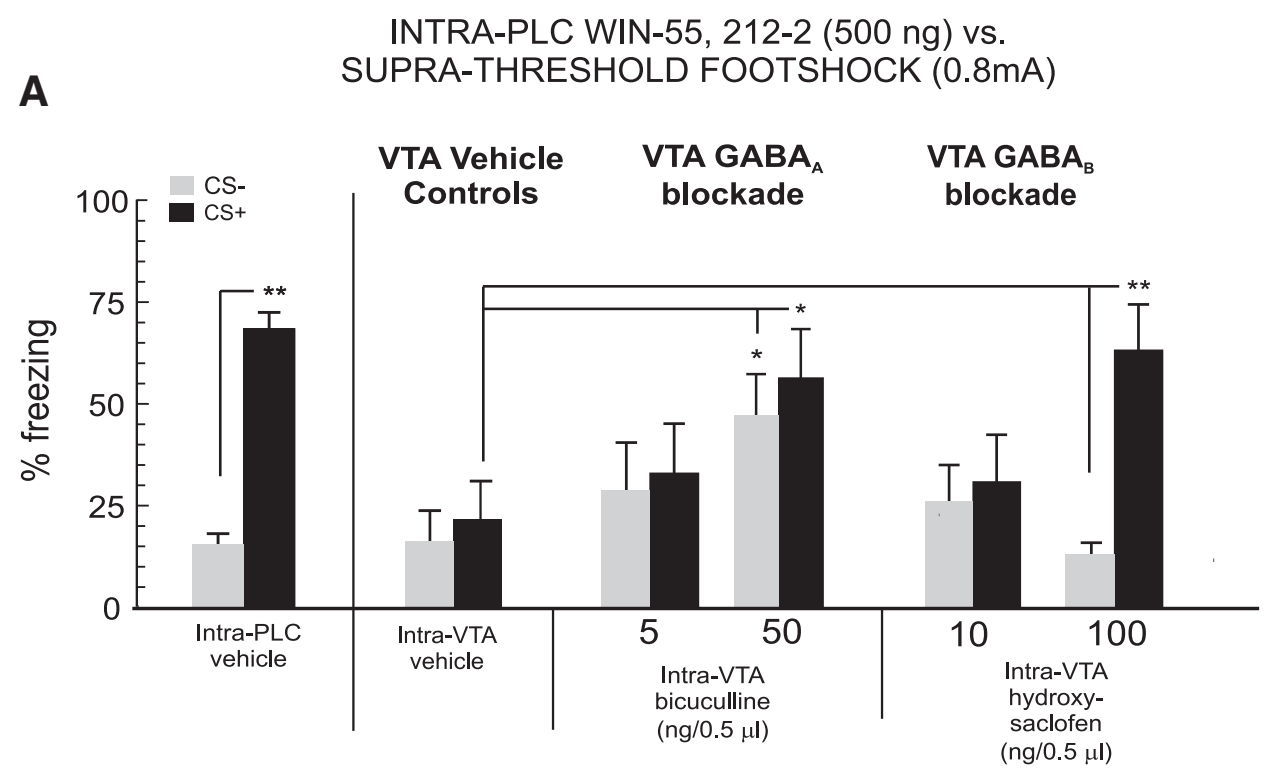

B

INTRA-PLC WIN-55, 212-2 (500 ng) vs. SUPRA-THRESHOLD FOOTSHOCK $(0.8 \mathrm{~mA})$

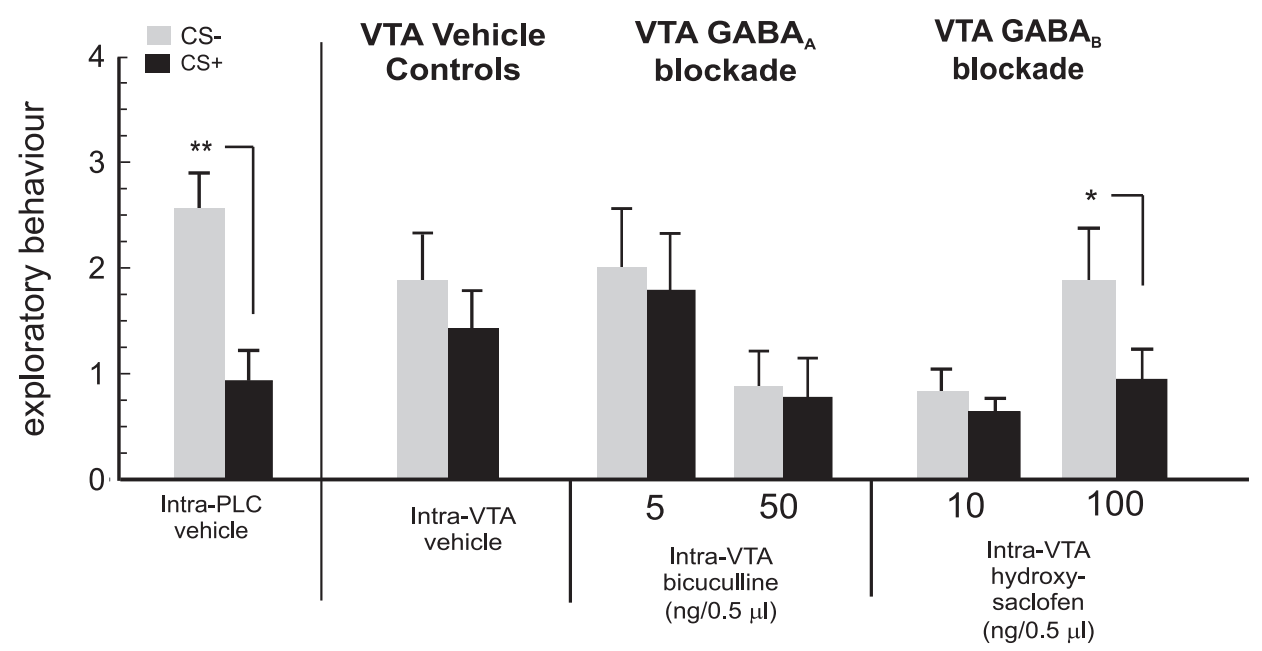

Figure 9. Effects of intra-VTA GABA and $G A B A_{B}$ receptor blockade on $(B 1$-mediated blockade of suprathreshold behavioral fear memory acquisition. $A$, Relative to vehicle controls $(n=8)$, intra-VTA GABA $A_{A}$ receptor blockade (bicuculline; $5-50 \mathrm{ng} / 0.5 \mu l ; n=7$ and $n=8$, respectively) dose dependently, but nonassociatively, increased fear-related freezing behavior induced by intra-PLC CB1 receptor activation with a higher dose of WIN 55,212-2 (500 ng/0.5 $\mu$ l) following both CS - and CS + conditioned cues. In contrast, GABA ${ }_{B}$ receptor blockade (hydroxy-saclofen; $10-100 \mathrm{ng} / 0.5 \mu \mathrm{l} ; n s=6$ per group) dose dependently restored associative fear memory formation specifically to CS + presentations. $B$, Similarly, intra-VTA GABA receptor blockade fails to restore associative suppression of freezing behaviors whereas this effect is rescued by intra-VTA GABA ${ }_{B}$ receptor blockade.

and treatment $\left(F_{(2,45)}=4.05, p<0.05\right)$. Post hoc analysis revealed a significant difference in exploratory behaviors between CS+ and CS - presentations in rats receiving a higher dose of hydroxysaclofen $(100 \mathrm{ng} / 0.5 \mu \mathrm{l})$, but no differences in intra-VTA vehicle rats or in rats receiving the lower dose of intra-VTA hydroxysaclofen (Fig. 9B). Thus, intra-VTA $\mathrm{GABA}_{\mathrm{B}}$ receptor blockade before intra-PLC WIN 55,212-2 (500 ng/0.5 $\mu \mathrm{l})$ was sufficient to rescue acquisition of associative fear memory formation both in terms of associative freezing behaviors and associative suppression of exploratory behavior.

\section{Discussion}

In the present report, intra-PLC cannabinoid CB1 receptor activation biphasically and dose dependently modulated the spontaneous firing frequency and bursting activity of VTA DAergic neurons and similarly mediated differential effects on behavioral measures of associative fear memory. Relatively lower doses strongly potentiated the acquisition of normally nonsalient associative fear memory while increasing firing and bursting activity of VTA DAergic neurons. In contrast, a relatively higher dose blocked acquisition of normally suprathreshold fear-conditioned memory while blunting the activity levels of VTA DAergic neurons. These results have several implications for understanding how intracortical cannabinoid signaling may relate to DA-related emotional-processing phenomena, in terms of behavioral and mesolimbic neuronal activity patterns.

Previous evidence implicates intra-mPFC CB1 receptor transmission as critical for the processing of emotionally salient associative memories, both behaviorally and neuronally. Thus, direct 
activation of $\mathrm{mPFC} \mathrm{CB} 1$ receptors strongly potentiates the emotional salience of normally nonsalient fear-conditioning stimuli (Laviolette and Grace, 2006). Furthermore, administration of $\mathrm{CB} 1$ receptor agonists potentiates associative neuronal responses to fear stimuli in mPFC neurons (Laviolette and Grace, 2006). Importantly, the present dose range of WIN 55,212-2 (50-500 $\mathrm{ng} / 0.5 \mu \mathrm{l}$ ) is pharmacologically specific to $\mathrm{CB} 1$ receptors and does not alter baseline levels of nociceptive or neuronal responsiveness to these levels of footshock (Laviolette and Grace, 2006; Ahmad et al., 2013), ruling out the possibility of confounding interactions with nociceptive processing. Together, this evidence demonstrates that intracortical cannabinoid signaling is a potent modulator of emotional processing, and is consistent with a wide body of evidence linking disturbances in intracortical CB1 transmission to emotional dysregulation.

For example, in schizophrenia patients, the dorsolateral prefrontal cortex shows increased CB1 receptor binding; an effect specifically pronounced in paranoid schizophrenia (Dean et al., 2001; Dalton et al., 2011). Recent evidence demonstrates diminished DA synthesis in regular marijuana users (Bloomfield et al., 2014) and evidence for reduced DA receptor levels in current or abstinent marijuana users (Urban et al., 2012; Albrecht et al., 2013). Such phenomena may seem inconsistent with evidence demonstrating that chronic marijuana use during adolescence may increase the likelihood of early adulthood psychosis (Andréasson et al., 1987; Hall and Degenhardt, 2011; Kuepper et al., 2011), an effect associated with hyper-DAergic activity (Kuepper et al., 2013). However, the present findings may suggest a concentration-dependent, biphasic CB1 receptor-mediated mechanism within the PLC regulating downstream mesolimbic DAergic activity to account for these seemingly divergent modulatory effects on DAergic signaling pathways.

Cannabinoids produce biphasic modulatory effects in the regulation of various behaviors. For example, cannabinoids produce hyperphagic responses at lower doses and hypophagic effects at higher doses, indicative of excitatory versus inhibitory influences on feeding-related motivational neural pathways (Bellocchio et al., 2010). A recent study from Katsidoni et al. (2013) demonstrated that whereas lower THC doses potentiated neural reward effects measured with rewarding brain stimulation, higher doses attenuated reward effects. Valjent and Maldonado (2000) reported that higher THC doses produced aversive behavioral effects, whereas lower doses produced reward, again demonstrating dose-related modulation of neural motivational pathways. Biphasic cannabinoid effects are not limited to behavior. Lower doses of intravenous THC increase cerebral metabolism in cortical and limbic structures (Margulies and Hammer, 1991) while higher doses suppress cerebral metabolism in these same circuits. Since cannabinoid transmission in the mPFC is known to inhibit GABAergic inhibitory substrates (Chiu et al., 2010; Hill et al., 2011; Kiritoshi et al., 2013), one potential mechanism for CB1mediated excitation of DAergic activity may be due to lower doses of WIN 55,212-2 removing GABAergic inhibition on PLC output neurons to the VTA. Indeed, we found that simultaneous activation of intra-PLC $\mathrm{GABA}_{\mathrm{A}} / \mathrm{GABA}_{\mathrm{B}}$ receptors was capable of blocking intra-PLC CB1 receptor activation-induced potentiation of subthreshold fear memory formation, while having no effect on the fear memory-blocking effects of the higher dose. Furthermore, given the importance of the PLC in the processing of fear-related information (Sierra-Mercado et al., 2011; SotresBayon et al., 2012), CB1-mediated potentiation of subthreshold fear memory may be related to the ability of intra-PLC CB1 transmission to enhance the intrinsic excitability of PLC output neu- rons via removal of intrinsic GABAergic inhibitory elements. The present findings suggest that this mechanism may ultimately potentiate emotional salience via descending outputs to DAergic neurons in the VTA. Alternatively, CB1 receptor activation could activate $\mathrm{CB} 1$ receptors on presynaptic DAergic fibers within the PLC, thereby modulating PLC output via DAergic feedforward modulation of GABAergic and/or pyramidal neurons. Such a mechanism is suggested by the present findings wherein intraPLC DA receptor blockade prevented CB1-mediated fear memory potentiation.

Our findings demonstrating differential roles for intra-VTA $\mathrm{GABA}_{\mathrm{A}}$ versus $\mathrm{GABA}_{\mathrm{B}}$ receptor transmission in the ability of a higher dose of intra-PLC CB1 receptor agonist to block the formation of associative fear memory have several implications. First, considerable evidence demonstrates preferential localization of $\mathrm{GABA}_{\mathrm{A}}$ receptors on non-DA, presumptive GABAergic VTA neurons, whereas $\mathrm{GABA}_{\mathrm{B}}$ receptors are functionally localized to the cell bodies of the VTA DA neurons. For example, $\mathrm{GABA}_{\mathrm{B}}$ receptor activation localized on VTA DA neurons can control the rewarding properties of various drugs of abuse (Wirtshafter and Sheppard, 2001; Leite-Morris et al., 2004). Furthermore, recording studies in the VTA have demonstrated that activation of $\mathrm{GABA}_{\mathrm{B}}$ receptors can directly hyperpolarize DA neurons or block glutamate-mediated excitation of the VTA DA neurons (Lacey, 1993; Seutin et al., 1994). Finally, intra-VTA $\mathrm{GABA}_{\mathrm{B}}$ receptor activation leads to decreased somatodendendritic release of DA within the mesolimbic pathway (Klitenick et al., 1992; Westerink et al., 1996). Given our findings that intraVTA blockade of $\mathrm{GABA}_{\mathrm{B}}$ signaling could rescue cortically induced blunting of emotional memory formation, this evidence would suggest that intra-PLC CB1-mediated blunting of DAergic neuronal activity in the VTA and concomitant blockade of emotional associative memory formation is mediated indirectly through a $\mathrm{GABA}_{\mathrm{B}}$ receptor substrate within the VTA. Furthermore, these results suggest that $\mathrm{PLC} \rightarrow \mathrm{VTA}$ inputs modulated by intra-PLC CB1 receptor transmission likely blunt DAergic transmission via actions on a VTA $\mathrm{GABA}_{\mathrm{B}}$ receptor substrate. Given that descending inputs from the PFC to the VTA are primarily GLUTergic in nature (Carr and Sesack, 2000a), this may suggest that higher doses of CB1 agonists in the PLC may inhibit tonic excitatory influences onto a downstream, VTA GABA $\mathrm{B}_{\mathrm{B}}$ receptordependent inhibitory input, thereby modulating a subpopulation of VTA DA neurons. For example, CB1 activation in the PFC is known to inhibit GLUTergic transmission and block learningrelated synaptic plasticity mechanisms such as long-term potentiation (Auclair et al., 2000). Furthermore, CB1 receptors strongly modulate excitatory GLUTergic transmission directly within the PFC (Lafourcade et al., 2007).

Interestingly, while blockade of VTA $\mathrm{GABA}_{\mathrm{A}}$ receptors did not rescue the acquisition of associative fear memory, we observed a nonassociative increase in freezing activity in response to both CS - and CS+ presentations. The majority of VTA GABA receptors are anatomically localized to non-DA, presumably GABAergic neurons (Churchill et al., 1992; Klitenick et al., 1992), where they can indirectly control the activity and output of VTA DA neurons via indirect, feedforward inhibitory mechanisms (Gysling and Wang, 1983; Kalivas et al., 1990; Kalivas, 1993). Indeed, blockade of intra-VTA $\mathrm{GABA}_{\mathrm{A}}$ receptors produces potent, DA-independent rewarding effects (Laviolette and van der Kooy, 2001; Laviolette et al., 2004). It is of interest that VTA GABAergic neurons send significant ascending projections to the mPFC, wherein they contact both interneuron and pyramidal neuron populations (Carr and Sesack, 2000b), which may in turn 
provide inhibitory or disinhibitory influences on mPFC outputs. Given our findings that intra-PLC CB1-mediated potentiation of subthreshold fear memory formation depends upon recurrent DA output to the mPFC, one possibility is that intra-VTA GABA receptor blockade, by increasing GABAergic output to the PLC, may in turn disinhibit descending inputs to VTA DAergic neurons, leading to a nonassociative increase in fear-related emotional processing. In contrast, $\mathrm{GABA}_{\mathrm{B}}$ receptor blockade may selectively prevent the inhibition of VTA DAergic neurons, thereby restoring associative fear memory processing within the VTA-PLC circuit. Importantly, it is possible that the observed neuronal and behavioral effects of intra-PLC CB1 receptor activation may be mediated via nondirect pathways between the PLC and VTA. For example, the mPFC sends functional inputs to the nucleus accumbens (Bossert et al., 2012), which in turn sends projections to VTA neuronal populations (Kalivas et al., 1993; Kalivas, 1993).

\section{Summary}

The present findings demonstrate biphasic behavioral and neuronal effects of intra-PLC CB1 receptor activation. While the current studies focused on the acute effects of cortical CB1 receptor activation, such dose-related effects of lower versus higher levels of CB1 receptor activation may suggest that high or chronic levels of exposure to CB1 receptor-activating drugs such as marijuana, may lead to a blunting of subcortical DAergic transmission, as suggested by recent clinical imaging studies (Urban et al., 2012; Albrecht et al., 2013; Bloomfield et al., 2014). Furthermore, the observed deficit in emotional associative memory induced by stronger intra-PLC CB1 activation may resemble emotional associative learning and memory deficits observed in schizophrenia patients (Jensen et al., 2008). Given prior evidence for CB1 receptor dysregulation in cortical regions of schizophrenia patients (Dean et al., 2001; Dalton et al., 2011), cannabinoid signaling dysregulation in the mPFC could theoretically predispose such individuals to abnormal DAergic transmission leading to abnormal amplification and/or pathological blunting of emotional processing.

\section{References}

Abush H, Akirav I (2012) Short- and long-term cognitive effects of chronic cannabinoids administration in late-adolescence rats. PLoS One 7:e31731. CrossRef Medline

Ahmad T, Lauzon NM, de Jaeger X, Laviolette SR (2013) Cannabinoid transmission in the prelimbic cortex bidirectionally controls opiate reward and aversion signaling through dissociable kappa versus $\mu$-opiate receptor dependent mechanisms. J Neurosci 33:15642-15651. CrossRef Medline

Albrecht DS, Skosnik PD, Vollmer JM, Brumbaugh MS, Perry KM, Mock BH, Zheng QH, Federici LA, Patton EA, Herring CM, Yoder KK (2013) Striatal $\mathrm{D}(2) / \mathrm{D}(3)$ receptor availability is inversely correlated with cannabis consumption in chronic marijuana users. Drug Alcohol Depend 128:52-57. CrossRef Medline

Andréasson S, Allebeck P, Engström A, Rydberg U (1987) Cannabis and schizophrenia. A longitudinal study of Swedish conscripts. Lancet 2:1483-1486. Medline

Andréasson S, Allebeck P, Rydberg U (1989) Schizophrenia in users and nonusers of cannabis. A longitudinal study in Stockholm County. Acta Psychiatr Scand 79:505-510. CrossRef Medline

Antoniadis EA, McDonald RJ (1999) Discriminative fear conditioning to context expressed by multiple measures of fear in the rat. Behav Brain Res 101:1-13. CrossRef Medline

Auclair N, Otani S, Soubrie P, Crepel F (2000) Cannabinoids modulate synaptic strength and plasticity at glutamatergic synapses of rat prefrontal cortex pyramidal neurons. J Neurophysiol 83:3287-3293. Medline

Bellocchio L, Lafenêtre P, Cannich A, Cota D, Puente N, Grandes P, Chaou- loff F, Piazza PV, Marsicano G (2010) Bimodal control of stimulated food intake by the endocannabinoid system. Nat Neurosci 13:281-283. CrossRef Medline

Bloomfield MA, Morgan CJ, Egerton A, Kapur S, Curran HV, Howes OD (2014) Dopaminergic function in cannabis users and its relationship to cannabis-induced psychotic symptoms. Biol Psychiatry 75:470-478. CrossRef Medline

Bossert JM, Stern AL, Theberge FR, Marchant NJ, Wang HL, Morales M, Shaham Y (2012) Role of projections from ventral medial prefrontal cortex to nucleus accumbens shell in context-induced reinstatement of heroin seeking. J Neurosci 32:4982-4991. CrossRef Medline

Carr DB, Sesack SR (2000a) GABA-containing neurons in the rat ventral tegmental area project to the prefrontal cortex. Synapse 38:114-123. CrossRef Medline

Carr DB, Sesack SR (2000b) Projections from the rat prefrontal cortex to the ventral tegmental area: target specificity in the synaptic associations with mesoaccumbens and mesocortical neurons. J Neurosci 20:3864-38673. Medline

Chiu CQ, Puente N, Grandes P, Castillo PE (2010) Dopaminergic modulation of endocannabinoid-mediated plasticity at GABAergic synapses in the prefrontal cortex. J Neurosci 30:7236-7248. CrossRef Medline

Churchill L, Dilts RP, Kalivas PW (1992) Autoradiographic localization of gamma-aminobutyric acid-A receptors within the ventral tegmental area. Neurochem Res 17:101-106. CrossRef Medline

Dalton VS, Long LE, Weickert CS, Zavitsanou K (2011) Paranoid schizophrenia is characterized by increased CB1 receptor binding in the dorsolateral prefrontal cortex. Neuropsychopharmacology 36:1620-1630. CrossRef Medline

Dean B, Sundram S, Bradbury R, Scarr E, Copolov D (2001) Studies on $[3 \mathrm{H}] \mathrm{CP}-55940$ binding in the human central nervous system: regional specific changes in density of cannabinoid-1 receptors associated with schizophrenia and cannabis use. Neuroscience 103:9-15. CrossRef Medline

Degenhardt L, Hall W, Lynskey M (2003) Exploring the association between cannabis use and depression. Addiction 98:1493-1504. CrossRef Medline

Fitzgerald ML, Mackie K, Pickel VM (2013) The impact of adolescent social isolation on dopamine $\mathrm{D} 2$ and cannabinoid CB1 receptors in the adult rat prefrontal cortex. Neuroscience 235:40-50. CrossRef Medline

French ED, Dillon K, Wu X (1997) Cannabinoids excite dopamine neurons in the ventral tegmentum and substantia nigra. Neuroreport 8:649-652. CrossRef Medline

Gessa GL, Melis M, Muntoni AL, Diana M (1998) Cannabinoids activate mesolimbic dopamine neurons by an action on cannabinoid CB1 receptors. Eur J Pharmacol 341:39-44. CrossRef Medline

Grace AA, Bunney BS (1983) Intracellular and extracellular electrophysiology of nigral dopaminergic neurons-1. Identification and characterization. Neuroscience 10:301-315. CrossRef Medline

Gysling K, Wang RY (1983) Morphine-induced activation of A10 dopamine neurons in the rat. Brain Res 277:119-127. Medline

Hall W, Degenhardt L (2011) Cannabis and the increased incidence and persistence of psychosis. BMJ 342:d719. CrossRef Medline

Hill MN, McLaughlin RJ, Pan B, Fitzgerald ML, Roberts CJ, Lee TT, Karatsoreos IN, Mackie K, Viau V, Pickel VM, McEwen BS, Liu QS, Gorzalka BB, Hillard CJ (2011) Recruitment of prefrontal cortical endocannabinoid signaling by glucocorticoids contributes to termination of the stress response. J Neurosci 31:10506-10515. CrossRef Medline

Jensen J, Willeit M, Zipursky RB, Savina I, Smith AJ, Menon M, Crawley AP, Kapur S (2008) The formation of abnormal associations in schizophrenia: neural and behavioral evidence. Neuropsychopharmacology 33:473479. CrossRef Medline

Kalivas PW (1993) Neurotransmitter regulation of dopamine neurons in the ventral tegmental area. Brain Res Brain Res Rev 18:75-113. CrossRef Medline

Kalivas PW, Duffy P, Eberhardt H (1990) Modulation of A10 dopamine neurons by gamma-aminobutyric acid agonists. J Pharmacol Exp Ther 253:858-866. Medline

Kalivas PW, Churchill L, Klitenick MA (1993) GABA and enkephalin projection from the nucleus accumbens and ventral pallidum to the ventral tegmental area Neuroscience 57:1047-1060. CrossRef

Katsidoni V, Kastellakis A, Panagis G (2013) Biphasic effects of $\Delta 9$ tetrahydrocannabinol on brain stimulation reward and motor activity. Int J Neuropsychopharmacol 16:2273-2284. CrossRef Medline 
Kiritoshi T, Sun H, Ren W, Stauffer SR, Lindsley CW, Conn PJ, Neugebauer V (2013) Modulation of pyramidal cell output in the medial prefrontal cortex by mGluR5 interacting with CB1. Neuropharmacology 66:170178. CrossRef Medline

Klitenick MA, DeWitte P, Kalivas PW (1992) Regulation of somatodendritic dopamine release in the ventral tegmental area by opioids and GABA: an in vivo microdialysis study. J Neurosci 12:2623-2632. Medline

Kuepper R, van Os J, Lieb R, Wittchen HU, Höfler M, Henquet C (2011) Continued cannabis use and risk of incidence and persistence of psychotic symptoms: 10 year follow-up cohort study. BMJ 342:d738, 2011 Mar 1. CrossRef Medline

Kuepper R, Ceccarini J, Lataster J, van Os J, van Kroonenburgh M, van Gerven JM, Marcelis M, Van Laere K, Henquet C (2013) Delta-9tetrahydrocannabinol-induced dopamine release as a function of psychosis risk: $18 \mathrm{~F}$-fallypride positron emission tomography study. PLoS One 8:e70378. CrossRef Medline

Lacey MG (1993) Neurotransmitter receptors and ionic conductances regulating the activity of neurones in substantia nigra pars compacta and ventral tegmental area. Prog Brain Res 99:251-276. CrossRef Medline

Lafourcade M, Elezgarai I, Mato S, Bakiri Y, Grandes P, Manzoni OJ (2007) Molecular components and functions of the endocannabinoid system in mouse prefrontal cortex. PLoS One 2:e709. CrossRef Medline

Lauzon NM, Bishop SF, Laviolette SR (2009) Dopamine D1 versus D4 receptors differentially modulate the encoding of salient versus nonsalient emotional information in the medial prefrontal cortex. J Neurosci 29: 4836-4845. CrossRef Medline

Laviolette SR, Grace AA (2006) Cannabinoids potentiate emotional learning plasticity in neurons of the medial prefrontal cortex through basolateral amygdala inputs. J Neurosci 26:6458-6468. CrossRef Medline

Laviolette SR, van der Kooy D (2001) GABA $_{\mathrm{A}}$ receptors in the ventral tegmental area control bidirectional reward signalling between dopaminergic and non-dopaminergic neural motivational systems. Eur J Neurosci 13:1009-1015. CrossRef Medline

Laviolette SR, Gallegos RA, Henriksen SJ, van der Kooy D (2004) Opiate state controls bi-directional reward signaling via GABAA receptors in the ventral tegmental area. Nat Neurosci 7:160-169. CrossRef Medline

Laviolette SR, Lipski WJ, Grace AA (2005) A subpopulation of neurons in the medial prefrontal cortex encodes emotional learning with burst and frequency codes through a dopamine D4 receptor-dependent basolateral amygdala input. J Neurosci 25:6066-6075. CrossRef Medline

Leite-Morris KA, Fukudome EY, Shoeb MH, Kaplan GB (2004) GABA Beceptor activation in the ventral tegmental area inhibits the acquisition and expression of opiate-induced motor sensitization. J Pharmacol Exp Ther 308:667-678. Medline

Lynskey MT, Glowinski AL, Todorov AA, Bucholz KK, Madden PA, Nelson EC, Statham DJ, Martin NG, Heath AC (2004) Major depressive disorder, suicidal ideation, and suicide attempt in twins discordant for cannabis dependence and early-onset cannabis use. Arch Gen Psychiatry 61: 1026-1032. CrossRef Medline

Margeta-Mitrovic M, Mitrovic I, Riley RC, Jan LY, Basbaum AI (1999) Immunohistochemical localization of $\mathrm{GABA}_{\mathrm{B}}$ receptors in the rat central nervous system. J Comp Neurol 405:299-321. CrossRef Medline

Margolis EB, Toy B, Himmels P, Morales M, Fields HL (2012) Identification of rat ventral tegmental area GABAergic neurons. PLoS One 7:e42365. CrossRef Medline

Margulies JE, Hammer RP Jr (1991) Delta 9-tetrahydrocannabinol alters cerebral metabolism in a biphasic, dose-dependent manner in rat brain. Eur J Pharmacol 202:373-378. CrossRef Medline

Oropeza VC, Mackie K, Van Bockstaele EJ (2007) Cannabinoid receptors are localized to noradrenergic axon terminals in the rat frontal cortex. Brain Res 1127:36-44. CrossRef Medline

Paxinos G, Watson C (2005) The rat brain in stereotaxic coordinates. San Diego, CA: Academic.

Pistis M, Porcu G, Melis M, Diana M, Gessa GL (2001) Effects of cannabinoids on prefrontal neuronal responses to ventral tegmental area stimulation. Eur J Neurosci 14:96-102. CrossRef Medline

Renard J, Krebs MO, Jay TM, Le Pen G (2013) Long-term cognitive impairments induced by chronic cannabinoid exposure during adolescence in rats: a strain comparison. Psychopharmacology 225:781-790. CrossRef Medline

Rey AA, Purrio M, Viveros MP, Lutz B (2012) Biphasic effects of cannabinoids in anxiety responses: $\mathrm{CB} 1$ and $\mathrm{GABA}_{\mathrm{B}}$ receptors in the balance of GABAergic and glutamatergic neurotransmission. Neuropsychopharmacology 37:2624-2634. CrossRef Medline

Seutin V, Johnson SW, North RA (1994) Effect of dopamine and baclofen on N-methyl-D-aspartate-induced burst firing in rat ventral tegmental neurons. Neuroscience 58:201-206. CrossRef Medline

Sierra-Mercado D, Padilla-Coreano N, Quirk GJ (2011) Dissociable roles of prelimbic and infralimbic cortices, ventral hippocampus, and basolateral amygdala in the expression and extinction of conditioned fear. Neuropsychopharmacology 36:529-538. CrossRef Medline

Smith MJ, Cobia DJ, Wang L, Alpert KI, Cronenwett WJ, Goldman MB, Mamah D, Barch DM, Breiter HC, Csernansky JG (2014) Cannabisrelated working memory deficits and associated subcortical morphological differences in healthy individuals and schizophrenia subjects. Schizophr Bull 40:287-299. CrossRef Medline

Sotres-Bayon F, Sierra-Mercado D, Pardilla-Delgado E, Quirk GJ (2012) Gating of fear in prelimbic cortex by hippocampal and amygdala inputs. Neuron 76:804-812. CrossRef Medline

Szutorisz H, DiNieri JA, Sweet E, Egervari G, Michaelides M, Carter JM, Ren Y, Miller ML, Blitzer RD, Hurd YL (2014) Parental THC exposure leads to compulsive heroin-seeking and altered striatal synaptic plasticity in the subsequent generation. Neuropsychopharmacology 39:1315-1323. CrossRef Medline

Tan H, Lauzon NM, Bishop SF, Bechard MA, Laviolette SR (2010) Integrated cannabinoid CB1 receptor transmission within the amygdalaprefrontal cortical pathway modulates neuronal plasticity and emotional memory encoding. Cereb Cortex 20:1486-1496. CrossRef Medline

Tan H, Lauzon NM, Bishop SF, Chi N, Bechard M, Laviolette SR (2011) Cannabinoid transmission in the basolateral amygdala modulates fear memory formation via functional inputs to the prelimbic cortex. J Neurosci 31:5300-5312. CrossRef Medline

Urban NB, Slifstein M, Thompson JL, Xu X, Girgis RR, Raheja S, Haney M, Abi-Dargham A (2012) Dopamine release in chronic cannabis users: a [11C]raclopride positron emission tomography study. Biol Psychiatry 71:677-683. CrossRef Medline

Valjent E, Maldonado R (2000) A behavioral model to reveal place preference to delta 9-tetrahydrocannabinol in mice. Psychopharmacology 147: 436-448. CrossRef Medline

Westerink BH, Kwint HF, deVries JB (1996) The pharmacology of mesolimbic dopamine neurons: a dual-probe microdialysis study in the ventral tegmental area and nucleus accumbens of the rat brain. J Neurosci 16:2605-2611. Medline

Wirtshafter D, Sheppard AC (2001) Localization of $\mathrm{GABA}_{B}$ receptors in midbrain monoamine containing neurons in the rat. Brain Res Bull 56: 1-5. CrossRef Medline

Xi ZX, Stein EA (1999) Baclofen inhibits heroin self-administration behavior and mesolimbic dopamine release. J Pharmacol Exp Ther 290:13691374. Medline 